\title{
Energy-saving design and implementation in metro weak current systems: a case study of the Kunming metro system
}

\author{
Chang Haili ${ }^{1}$
}

Received: 18 September 2021/Revised: 13 October 2021/Accepted: 17 October 2021/Published online: 4 December 2021

(C) The Author(s) 2021

\begin{abstract}
With the accelerated urbanization in China, along with the growing scale of the metro transportation network, the energy consumption of metro systems continues to increase. To face the tough challenge of climate change, China has put forward the goal of peak carbon emissions by 2030 and achieving carbon neutrality by 2060. Energy consumption has become a serious burden for metro operation companies, since $10.2 \%$ of the total operational budgets is spent on electricity. Thus the development of methods to realize energy saving and emission reduction has become a major challenge for metros. In this study we conduct an in-depth research and analysis on metro energy load classification and energy management, focusing in particular on the design and usage of power supply systems for metro weak current electromechanical systems, including tunnel fans, station air conditioners, station escalators, automatic ticketing equipment, screen doors, drainage pumps, sewage pumps, platform doors, communication systems, signals, integrated monitoring systems, automatic ticketing and various lighting equipment and facilities. It is proposed that the five weak current systems, namely platform doors, communication systems, signals, integrated monitoring and automatic fare collection, should adopt a backup power supply. In order to ensure the reliable operation of all weak current systems in the station, the traditional decentralized power supply mode is changed to a centralized power supply and
\end{abstract}

Chang Haili

changhaili@bjuci.com.cn

1 Beijing Urban Construction Intelligent Control Co. Ltd, Beijing 100028, China uninterruptible power supply (UPS) $(1+1)$ parallel double-bus system. At the same time, combined with the data on equipment quantity, station passenger flow and station building floorage, the Boruta algorithm is used to filter out the equipment related to station weak current energy consumption, and a principal component analysis (PCA) algorithm is used to further reduce the dimensions of the filtered features to reduce the algorithm overhead of the subsequent quota analysis model. The XGBoost algorithm is used to establish a prediction model for station weak current system energy consumption. Analysis shows that there is a strong correlation between the energy consumption quota and the equipment quantity as well as station building floorage. By setting different metering instruments for power supply circuits, the main energy consumption data are collected to meet the requirements for graded metering of metro energy consumption, and then the energy consumption quota for the station weak current system is reasonably predicted. By adding metering instruments to the power supply circuits of different areas and equipment, the energy consumption of the weak current system can be measured and monitored in different grades. The combination of the energy management platform and energy consumption quota provides the basis for energy management of each energy-consuming unit, and ultimately realizes energy saving and reduced consumption.

Keywords Metro - Energy-saving - Weak current system · Uninterruptible power supply (UPS) · Energy consumption prediction - Measuring instruments - Energy consumption quota

Communicated by Baoming Han. 


\section{Introduction}

In recent years, with the acceleration of urbanization in China, problems such as the rapid growth of urban populations, the growing demand for resources and environment, the urgent need to improve the unified management of cities and the unbalanced development of urban areas have become increasingly serious. As a punctual, fast, environmentally friendly, large-capacity and land-saving transportation mode, rail transit has gradually become a focus to achieve urban and regional development goals and spatial development strategies.

By the end of 2019, 208 urban rail transit lines had been opened in 40 cities across China, with a total length of $6736.2 \mathrm{~km}$, including $5180.6 \mathrm{~km}$ of metros, accounting for 76.9\%. A total of 3982 metro stations have been put into operation (transfer stations are not counted repeatedly), and a total of 317 car depots and parking lots have been put into operation [1].

According to incomplete statistics, Beijing handled 3.96 billion passenger trips in 2019, and Shanghai handled 3.88 billion passenger trips. The average daily passenger traffic in the two cities exceeded 10 million passengers. The four largest megacities, Beijing, Shanghai, Guangzhou and Shenzhen, contribute more than half of the total passenger traffic in China.

At present, electric traction is used in metros all over the world, and the supply and transmission of electrical energy is important to guarantee the safe and reliable operation of metros. In addition to supplying power to metro vehicles, electrical energy also supplies power to metro electromechanical equipment, including tunnel fans, station air conditioners, station escalators, automatic fare collection equipment, screen doors, drainage pumps, sewage pumps, platform doors, communication systems, signals, integrated monitoring systems, automatic fire alarm equipment, environmental and equipment monitoring equipment and various lighting facilities.

As the main energy source for metro systems, electrical energy consumption has continued to increase with the developing transportation network, and its magnitude cannot be ignored. In 2019, according to the statistical calculation of data reported by the operating units, the total power consumption of urban rail transit was 15.26 billion $\mathrm{kWh}$, and year-on-year growth was $15.5 \%$. Electricity charges account for $10.2 \%$ of operating costs [1]. With the continuous expansion of the urban rail transit network, its energy consumption will further increase, which will impose a heavy burden on urban energy supply, and at the same time, metro operators will face rising cost pressure.

In 2017, China issued the Comprehensive Work Plan for Energy Conservation and Emission Reduction in the
Thirteenth Five-Year Plan, which requires vigorous development of public transportation, and clearly requires the share of public transportation in large cities to reach $30 \%$ by 2020 .

On September 22, 2020, at the general debate of the 75th UN General Assembly, President Xi Jinping announced that China will increase its national independent contribution, adopt more powerful policies and measures, and strive to achieve the goal of "Peak carbon emissions by 2030 and achieving carbon neutrality by 2060" [2].

Against the background of energy saving and emission reduction, energy-saving technologies of metro systems have been applied to metro design, and energy-saving awareness has been implemented in actual metro operation. Some metro companies have set up an energy management platform to monitor and record metro energy consumption, analyze the collected basic data, manage energy quotas and implement cost accounting, which requires correcting waste behavior to improve the economic benefits of enterprises. At present, the configuration of meters in a metro energy management system can be basically divided into four levels [3]; the specific classification is shown in Table 1.

In the existing metro companies, in terms of energy meter allocation, typically only secondary meters are installed on the operation lines to measure the power consumption of vehicle traction and power lighting, to monitor the overall energy consumption of station and vehicle traction. The main reasons that only secondary meters are installed are as follows.

(1) Considering the high management cost, for example, the traditional metro electromechanical and weak current systems are designed and constructed separately due to various professional systems. For example, the weak current system is divided into five systems: signal, communication, integrated monitoring, automatic fare collection and platform door systems. There are molecular systems in each system, and as a result, the design and construction requirements of various disciplines and subsystems are not unified, and the later operation is carried out in different respective departments. Because of the lack of overall planning, it is difficult to realize the unified installation of meters, resulting in a serious lack of itemized measurement data for the power consumption of the main electrical equipment (such as fans, water pumps, escalators, platform doors, signals, communication systems).

(2) Since the existing metro lines in some cities were built some time ago, the original system needs to be transformed to build an energy management system and add meters. For example, each system of the 
Table 1 Meter configuration of a metro energy management system

\begin{tabular}{|c|c|c|c|c|}
\hline Meter level & First level & Second level & Third level & Fourth level \\
\hline $\begin{array}{c}\text { Installation } \\
\text { position }\end{array}$ & $\begin{array}{l}\text { Main } \\
\text { incoming } \\
\text { line of } \\
\text { main } \\
\text { substation }\end{array}$ & $\begin{array}{l}\text { Power supply for vehicle traction, } \\
\text { electromechanical equipment and } \\
\text { lighting }\end{array}$ & $\begin{array}{l}\text { Outgoing power of } 0.4 \mathrm{kV} \text { switch } \\
\text { cabinet of substation in each } \\
\text { station }\end{array}$ & $\begin{array}{l}\text { All outgoing meters of the whole } \\
\text { weak current equipment and the } \\
\text { switchgear in the environmental } \\
\text { control room }\end{array}$ \\
\hline $\begin{array}{l}\text { Measuring } \\
\text { range }\end{array}$ & $\begin{array}{l}\text { Total } \\
\text { incoming } \\
\text { power of } \\
\text { main } \\
\text { substation }\end{array}$ & $\begin{array}{l}\text { Electric quantity of two incoming } \\
\text { lines of traction substations at } \\
\text { each station and base, power } \\
\text { transformer and outgoing line } \\
\text { quantity of station and base }\end{array}$ & $\begin{array}{l}\text { Ventilation, lighting, elevator, } \\
\text { escalator, residual elevator, } \\
\text { drainage pump, sewage pump, } \\
\text { automatic fare collection system, } \\
\text { substation power, commercial } \\
\text { power, integrated monitoring } \\
\text { equipment, communication } \\
\text { equipment and signal equipment }\end{array}$ & $\begin{array}{l}\text { Gate, IT equipment, ride } \\
\text { information display screen, } \\
\text { camera, broadcast horn, air } \\
\text { conditioning unit, various fans, } \\
\text { chillers, refrigeration pumps, } \\
\text { cooling pumps and cooling tower } \\
\text { fans }\end{array}$ \\
\hline
\end{tabular}

weak current system has an independent backup power supply and distribution system, the transformation cost is high, and the utilization value of the collected energy measurement data is uncertain, which makes it more difficult for the metro company to build and utilize the energy metering network.

For these reasons, even if the metro company has built an energy consumption statistics and monitoring system, most of them only achieve a measurement range of level II, and only measure the total amount of the system or the total amount of the local range of energy consumption. The energy consumption data provided are only the common energy consumption data for local areas and multiple equipment, but do not measure and collect the energy consumption of the main energy-consuming equipment. Moreover, real-time synchronous statistical measurement data are not achieved, and the energy consumption process cannot be monitored and managed in real time.

At the same time, for energy management, the energy consumption quota includes an energy consumption quota per equipment and per process, which are important indices to evaluate the energy efficiency level and energy utilization rate of the project. At present, there is no energy consumption quota standard for the transportation field in China, but for the energy consumption and energy saving goal, the evaluation index of station energy consumption is given in the Beijing local standard evaluation method of energy consumption of urban rail transit (DB11/T1035.2013). The local standard of Jiangsu Province, code for operation energy consumption calculation and energy conservation management of urban rail transit (metro), provides the recommended value for metro operation energy consumption in the statistical reporting period, such as $100 \mathrm{kWh} / \mathrm{m}^{2}$ for underground stations and $90 \mathrm{kWh} / \mathrm{m}^{2}$ for aboveground stations, and encourages its metro operation companies to achieve its recommended value. Among them, energy consumption data are mainly the data from energy meters collected in the process of energy use. Therefore, for an energy consumption quota, energy measurement data are the basis for energy users to formulate energy consumption quota standards.

The metro company lacks a complete energy metering network and cannot realize the energy metering of the main energy-consuming equipment. For energy management, the main defects are as follows.

(1) Unable to measure and evaluate the details of the energy consumption process of end load equipment in a timely manner.

(2) Unable to reasonably predict the energy consumption of equipment, which is convenient for scientific management.

(3) The energy consumption data cannot be analyzed and compared with the energy-saving effect, and the abnormal energy consumption cannot be found in time, the energy consumption loopholes can be eliminated, the loss of energy consumption can be reduced, and the energy consumption process cannot be finely managed.

To sum up, the energy use of the metro is not only related to energy conservation and building an energysaving city, but also directly related to the enterprise operation benefits of the metro company and the government financial subsidies to the metro company. Although most metro companies carry out energy-saving upgrading and transformation, there is also a lack of comparison and management of corresponding energy consumption quota data after energy-saving measures are taken, so it is impossible to assess whether the energy-saving technology and equipment utilized achieve the expected effect. Therefore, we should realize the full load measurement of endpoint equipment, build an energy measurement 
network, strengthen the value mining of energy measurement data, and realize the energy efficiency monitoring and management of the overall energy consumption facilities and professional systems of the ground.

Based on the Jinchuan Road station of Kunming Metro Line 4 in Kunming, Yunnan Province of China, we design the system and meter energy data of different levels, ranging from the power supply system of the whole station to the endpoint weak current electric equipment. With the 5-month measurement data, we predict the energy consumption of the equipment of the main weak current system of the station through the machine learning method to provide its energy consumption quota and optimize the energy consumption management of weak current system. Finally, it is extended to the energy consumption quota management of the whole line and the whole system to realize energy conservation and emission reduction. The specific steps are as follows.

(1) Collecting relevant data required for this subject, such as basic data of Jinchuan Road Station of Kunming Metro Line 4 and load statistics of energyconsuming equipment.

(2) Optimizing the distribution cabinet of the UPS system, and planning the range of the electrical energy meter according to the region.

(3) Through machine learning on the collected data, the energy consumption quota of the weak current system of the station of Kunming Metro Line 4 is established, which further lays the foundation for the energy consumption quota of the station.

\section{Power supply requirements and present situation of the metro weak current system}

The main energy used and consumed by the metro includes electricity, water, fuel oil and gas. Most of the energy consumption in vehicle operation and electromechanical equipment is electrical energy. Water is also consumed in air conditioning equipment, and fuel oil and gas are consumed in the maintenance of equipment. However, the main energy consumption is still electrical energy. Therefore, to understand the current situation of metro energy consumption, we must understand the metro power supply system. The metro power supply system mainly includes the external power supply, main substation, step-down substation, traction substation, train traction power supply system, station power lighting power supply system and power monitoring system. The main power systems include the traction power supply and lighting power supply systems. The traction power supply system includes the traction substation and traction network, and the lighting power supply system includes the step-down substation and power lighting distribution system [4].

\subsection{Metro power supply requirements and load classification}

The overall power system of the metro industry is generally divided into the following parts: external power supply, main substation, traction step-down substation, stray current corrosion protection system and power monitoring system. The specific structure is shown in Fig. 1.

(1) The external power supply of the metro power supply system is the external urban power grid supplied by the main substation of the metro power supply system. There are three power supply schemes of the external power supply: centralized power supply, decentralized power supply and hybrid power supply. The centralized power supply usually introduces two power sources from the $110 \mathrm{kV}$ side of the urban power grid. According to the requirements of the metro design code, at least one power source is a dedicated line.

(2) The main function of the main substation is to receive external high-voltage power (usually $110 \mathrm{kV}$ ) and provide medium-voltage power (usually $35 \mathrm{kV}$ or $10 \mathrm{kV}$ ) for the traction substation and step-down substation after step-down. The main substation is suitable for the centralized power supply. The connection mode of the main substation is line-type or bridge-type.

(3) The function of the traction power supply system is to transform AC medium voltage into DC $1500 \mathrm{~V}$ or DC $750 \mathrm{~V}$ after step-down rectification, and to provide the traction power supply for metro trains. The system includes a traction substation and traction network, which includes the catenary and return network. Overhead catenary (DC $1500 \mathrm{~V})$ and contact rail (DC $1500 \mathrm{~V}$ or $750 \mathrm{~V}$ ) are two suspension modes. At present, most metros use the running rail as the return network, while a few metros use a separate return rail.

(4) The main function of the lighting power supply system is to step down AC medium voltage $(35 \mathrm{kV}$ or $10 \mathrm{kV}$ ) to AC $220 \mathrm{~V}$ and AC $380 \mathrm{~V}$ which can be used by the electromechanical equipment, and provide power for various electromechanical and weak current equipment required for operation.

(5) The stray current leaks from the running rail, flows into the ground through the metro track bed, and then flows back from the ground to the rail return point. Since the rail is buried on the ground surface, which makes it easy to find and replace damaged 
Fig. 1 Power system logic diagram of metro industry

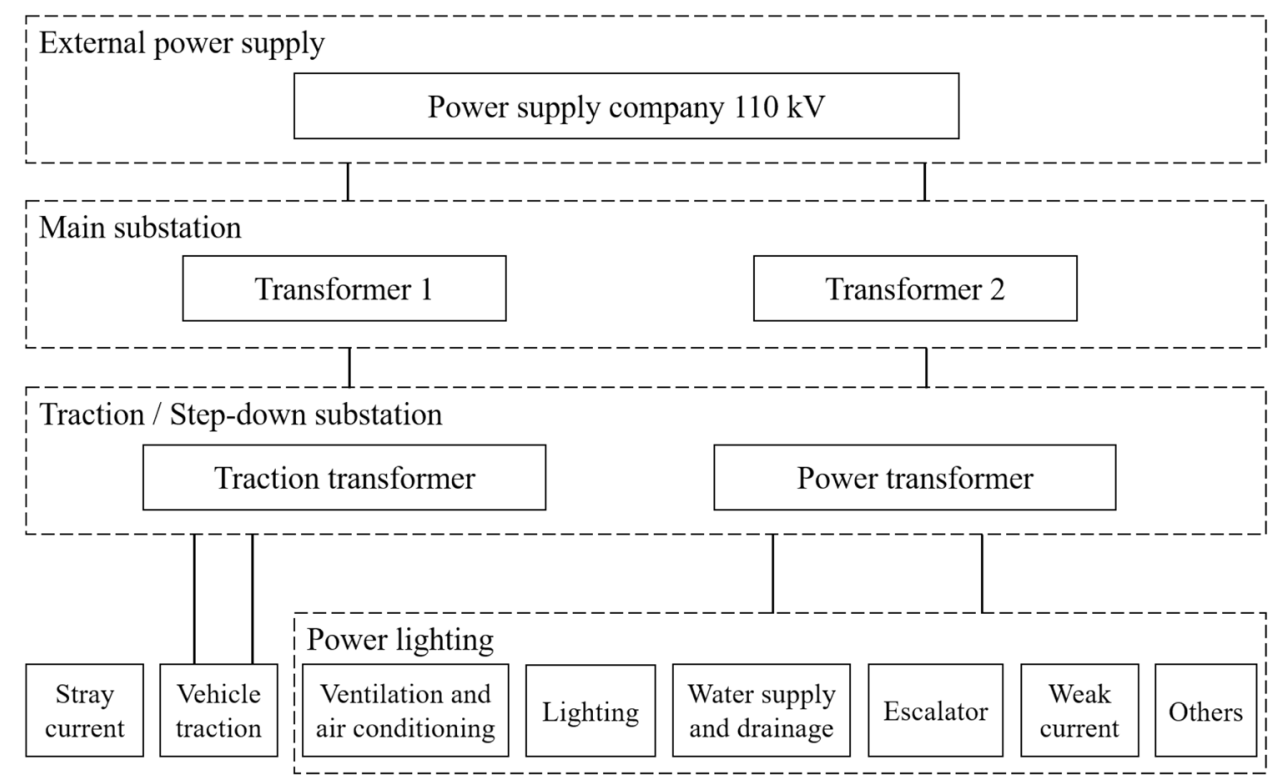

parts, the stray current corrosion is not very harmful. However, because the steel bars of the main structure and metal pipelines of the metro are buried underground, corrosion is not easy to detect, so stray current corrosion is very harmful to these steel bars and metal pipelines. Therefore, the main function of the stray current corrosion protection system is to reduce stray current caused by the DC traction power supply and prevent it from spreading to the outside world, to avoid electrical corrosion of stray current to the main structure of the urban rail transit and its adjacent structural steel bars and metal pipelines, and to monitor stray current and corrosion protection.

(6) The main function of the power monitoring system is to collect and monitor remote data of the metro substation, step-down substation, and catenary and other equipment in real time. In the metro control center, electric power dispatchers carry out telemetry, remote communication, remote control and remote adjustment control on the main electrical equipment through a dispatching terminal, communication channel and substation integrated automation system, to realize the operation and management of the whole metro power supply system.

\subsection{Classification requirements and standard of metro power load}

The metro power supply system is designed to satisfy different electrical energy requirements of different metro users. Therefore, it is necessary to classify the different power loads. The power load is divided into class I, class II and class III load according to the requirements for power supply reliability and the impact of power loss [4]. The most important electrical energy user is defined as the class I load user. According to the standard requirements, the class I load must be powered by a double power supply and double circuit line to ensure normal operation of the load. For particularly important loads in class I, an emergency power supply must be equipped and separated from other loads. The standard requires that the secondary load adopt a dual power input mode and single circuit special line power supply. The class III load can be powered by a single power supply and single circuit line [4]. The classification of power lighting load is shown in Table 2.

In metro power supply, in addition to distinguishing three different loads, some individual class I loads are defined as particularly important loads and must be equipped with an uninterruptible power supply (UPS). They include "automatic fire alarm system equipment, environment and equipment monitoring system equipment, special communication system equipment, signal system equipment, substation operation power supply, underground station and section emergency lighting" [4].

The power supply quality and continuity of these loads are very important for the safe and reliable operation of the metro system. A UPS is set for especially important loads. These loads of are shown in Table 3.

From the above standard requirements and application requirements, it can be seen that all of the especially important loads are the metro weak current system. Thus, the scientific application and coordination of the power supply of the metro station weak current system can ensure the safe and stable operation of the urban metro and rail 
Table 2 Classification of power lighting load

\begin{tabular}{|c|c|c|}
\hline Primary load & Secondary load & Tertiary load \\
\hline Automatic fire alarm system equipment & Passenger information system & Interval maintenance equipment \\
\hline $\begin{array}{l}\text { Electrical insulation equipment for fire water pumps and fire water } \\
\text { pipes }\end{array}$ & $\begin{array}{l}\text { Substation maintenance power } \\
\text { supply }\end{array}$ & Auxiliary room power outlet \\
\hline Smoke control fan and all kinds of fire smoke exhaust valves & $\begin{array}{l}\text { Lighting of public areas such as } \\
\text { ground stations, halls and } \\
\text { platforms }\end{array}$ & $\begin{array}{l}\text { Station air conditioning } \\
\text { refrigeration and water } \\
\text { system equipment }\end{array}$ \\
\hline Fire prevention (roller shutter) door and escalator for fire evacuation & Auxiliary room lighting & Advertising lighting \\
\hline Fire elevator & Ordinary fan & Cleaning equipment \\
\hline Emergency lighting & Dredge pump & Electro-heat installation \\
\hline Main drainage pump & Elevator & $\begin{array}{l}\text { Training and simulation system } \\
\text { equipment }\end{array}$ \\
\hline Rain water pump & $\begin{array}{l}\text { General lighting of escalators and } \\
\text { moving sidewalks for non-fire } \\
\text { evacuation }\end{array}$ & \\
\hline $\begin{array}{l}\text { Flooding doors and electrical equipment that still need to be used in } \\
\text { fire or other disasters }\end{array}$ & $\begin{array}{l}\text { Automatic fare collection } \\
\text { maintenance test system }\end{array}$ & \\
\hline $\begin{array}{l}\text { Communication system equipment (including special communication } \\
\text { system equipment, public security communication system } \\
\text { equipment and civil communication system equipment) }\end{array}$ & Power of the depot and parking lot & \\
\hline \multicolumn{3}{|l|}{ Signal system equipment } \\
\hline \multicolumn{3}{|l|}{ Integrated monitoring system equipment } \\
\hline \multicolumn{3}{|l|}{ Electric power monitoring system equipment } \\
\hline \multicolumn{3}{|l|}{ Environment and equipment monitoring system equipment } \\
\hline \multicolumn{3}{|l|}{ Access control system equipment } \\
\hline \multicolumn{3}{|l|}{ Security facilities } \\
\hline \multicolumn{3}{|l|}{$\begin{array}{l}\text { Automatic fare collection equipment (including disaster recovery } \\
\text { system, line control center computer system, station computer } \\
\text { system and station terminal equipment) }\end{array}$} \\
\hline \multicolumn{3}{|l|}{ Sorting system } \\
\hline \multicolumn{3}{|l|}{ Platform door equipment } \\
\hline \multicolumn{3}{|l|}{ Substation operating power supply } \\
\hline \multicolumn{3}{|l|}{ Lighting of public areas such as underground stations and platforms } \\
\hline Underground interval lighting & & \\
\hline Boiler room equipment in heating area & & \\
\hline
\end{tabular}

transit, and avoid the potential safety hazards and accidents of the metro weak current system. Therefore, the weak current system needs to be equipped with a UPS to ensure the reliability and continuity of power supply to these important systems.

\subsection{Power supply system of the metro weak current system}

The power supply of the metro weak current system requires high reliability, so a UPS must be set to ensure quality and continuity of power equipment. The main function of a UPS is to continuously provide AC to the load. It is an independent power supply with high quality, high stability and high reliability. The UPS realizes an AC uninterrupted power supply and purifies the municipal power into stable and pure $\mathrm{AC}$, and at the same time, it cooperates with the battery pack to realize continuous power supply in the case of power failure. Therefore, the UPS system has been widely used [5-7].

The UPS system is generally composed of power input circuits including the main circuit, bypass and battery, rectifier (REC) for $\mathrm{AC} / \mathrm{DC}$ conversion, inverter (INV) for DC/AC conversion, inverter and bypass output switching circuit, energy storage battery and other main parts. The schematic diagram of UPS composition is shown in Fig. 2.

When the commercial power of the UPS is normal, the commercial power is first converted into DC by a rectifier, then into $\mathrm{AC}$ by an inverter, and then output to the load after electrical isolation, ensuring that the output electrical 
Table 3 Especially important loads in metro stations

\begin{tabular}{ll}
\hline $\begin{array}{l}\text { Serial } \\
\text { number }\end{array}$ & System and equipment \\
\hline 1 & Signal equipment \\
2 & Special communication equipment \\
3 & Integrated monitoring equipment \\
4 & Power supply of graphic display device of automatic fire alarm system, fire communication equipment \\
5 & Environment and equipment monitoring system \\
6 & Automatic fare collection equipment (including disaster recovery system, line control center computer system, station \\
7 & $\quad$ computer system and station terminal equipment) \\
8 & Porting system \\
9 & Dlatform door equipment \\
10 & Emergency lighting \\
\hline
\end{tabular}

Fig. 2 Schematic diagram of UPS composition

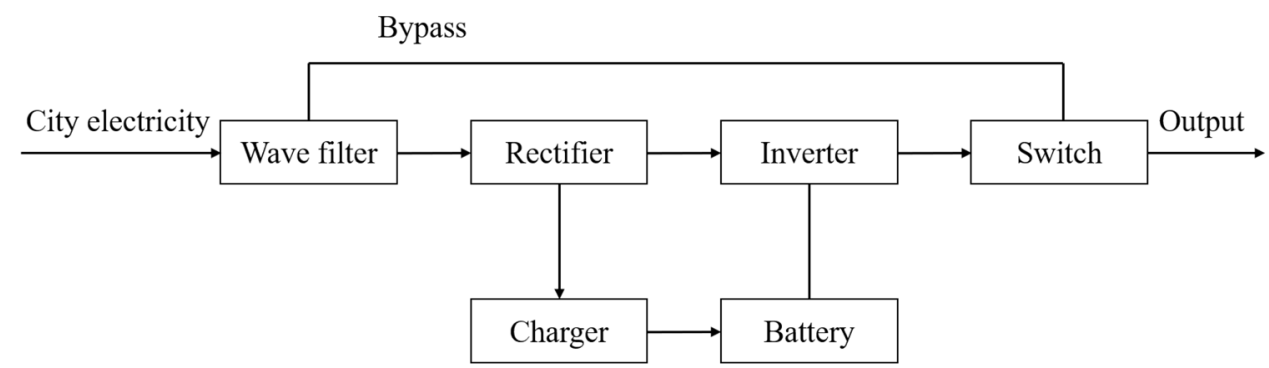

energy is regenerated and purified completely independently of the commercial power. When the commercial power is interrupted, the battery is converted into AC output through the inverter to ensure the uninterrupted normal power supply of the load.

UPS and independent power distribution cabinets are set for traditional weak current systems. The details are shown in Fig. 3.

\subsection{Present status of metro energy conservation and emission reduction}

There are three main ways to achieve the goal of energy saving and emission reduction and to improve the energy use rate for metros: management energy saving, structural energy saving and technical energy saving.

Structural energy saving mainly involves adjustment of the energy structure. The metro industry has introduced solar energy, which promotes the environmental benefits of photovoltaic power consumption and reduces the economic costs of urban rail operation. It also has the social benefits of improving energy utilization forms and satisfying people's desire for green travel [8].

From the perspective of technical energy saving, many metros have now put forward a structural improvement method of energy-saving slope through the optimization design of line structure to effectively save energy combined with the step-by-step situation of metro energy consumption, for the traction power supply of trains in the main energy-consuming equipment [9]. Also, regenerative braking technology, combined with the adjustment of the operation chart of the network operation, and integrated solutions are used to save energy [10-14].

As for the main factors affecting the environment of the station platform and station hall, piston wind, train heat production, particulate matter and other pollution and noise mainly come from the tunnel [15], and energy saving is realized through the screen door system which separates the platform from the station tunnel $[16,17]$. The design of power lighting and distribution for stations is carried out according to the principle of a graded load power supply, and various loads are divided into grades I, II or III according to their importance. The power supply system is simplified and the distribution equipment is saved. Adopting centralized reactive power automatic compensation and decentralized reactive power compensation measures improves the power factor and reduces line loss. In the station lighting system, high-efficiency and energysaving light sources and lamps and lanterns are mainly selected. In the escalator and fan system, frequency 
Fig. 3 UPS diagram of traditional weak current system
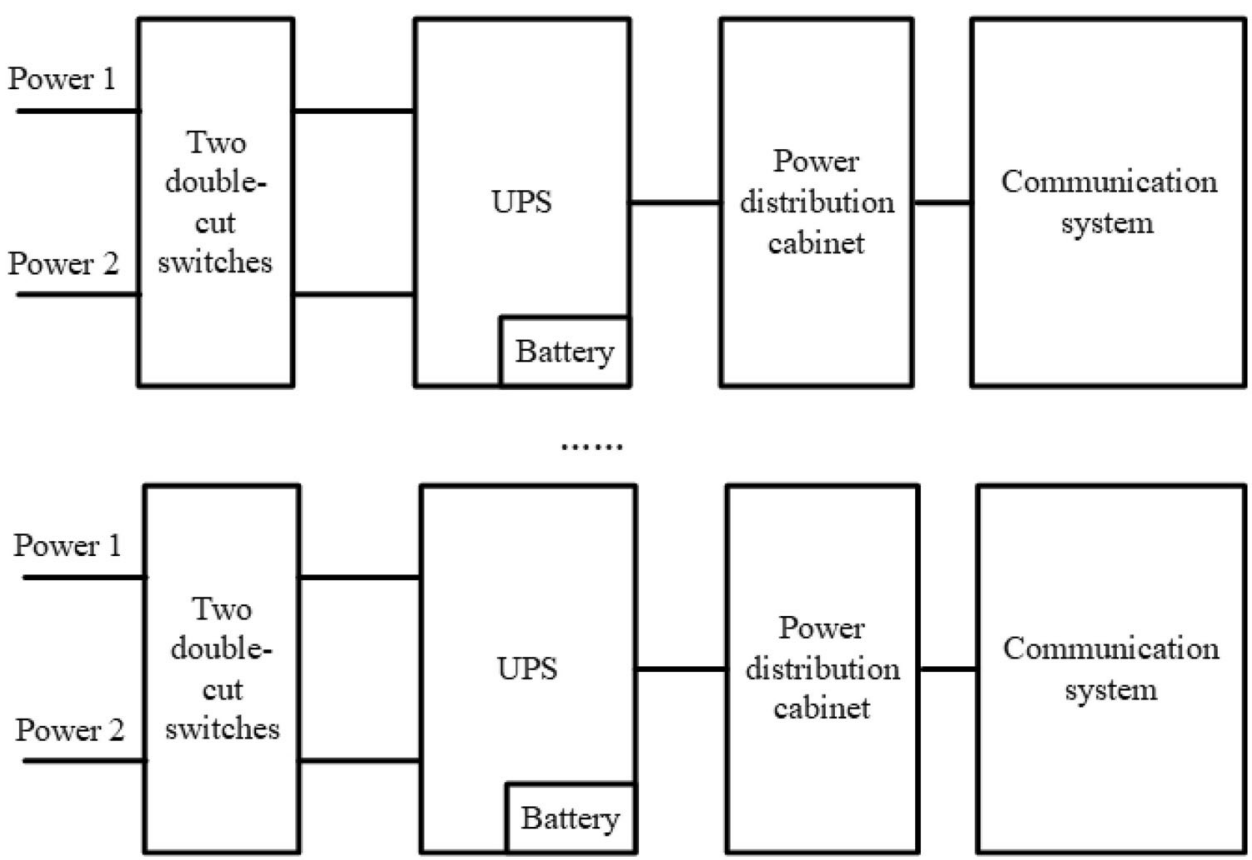

conversion control is selected to save equipment power consumption. At the same time, the management is strengthened. After the morning and evening peaks, some public lighting equipment is turned off, and the escalator operates at low speed by frequency conversion [18-23].

From the aspect of management and energy saving, many metro companies have established their own energy management platforms, such as Beijing Metro and Nanjing Metro, which have set up their own energy consumption data models [24, 25]. Beijing-Hong Kong Metro, Guiyang Metro and Harbin Metro have also established their own energy management platforms [26-29]. The energy management platforms have realized the automatic and realtime collection of energy consumption data for each link of the power supply system in the form of classification, subitem and household. In August 2019, the China Urban Rail Transit Association and China Building Energy Conservation Association jointly issued the group standard "Evaluation Standard for Green Urban Rail Transit Stations", which put forward a detailed measurement function of power consumption of different systems and different types of equipment and the evaluation requirements for setting up energy management systems [30].

In theory, energy consumption measurement is a precondition to realize energy saving and emission reduction in management. But in practice, it is realized by manual meter reading, copying the grid entrance settlement meter of the substation, and there is basically no meter in the subsequent links, so it is impossible to practice better quota management [20,31].
For different buildings, the energy consumed to provide people's comfort (e.g. air conditioning, heating) can be properly considered in order to ensure the basic operation of the building, and the energy-saving goal can be achieved by restraining extravagant energy consumption, which can be achieved by formulating energy consumption quotas. The energy consumption quota should refer to the energy consumed to meet the basic operating requirements of buildings [32, 33].

Therefore, it is important to collect the current total energy consumption data for stations and energy consumption data for various equipment, combined with passenger flow data, environmental data and other data, and analysis and mining through a big data platform, in order to achieve continuous learning and improvement of the prediction model. Experts and scholars at home and abroad have put forward two machine learning methods, support vector regression (SVR) and random forest regression (RFR), to predict the energy consumption of metros [34]. A method for building a time series analysis model of metro energy consumption has been proposed using correlation analysis software and performing stationarity tests, data difference and order analysis to predict and analyze metro energy consumption in the next few years by comparing theoretical and actual energy consumption values [35]. Some experts have also put forward a building energy consumption prediction method (principal component analysis-radial basis function [PCA-RBF]) combining PCA with a neural network, which effectively improves the prediction accuracy of building energy consumption [36]. International scholars have put forward an intelligent 
method for predicting the energy consumption of metro stations by simulating the energy consumption system of a Hong Kong ground station based on an artificial neural network algorithm, which can be used to predict the weekly power consumption of metro stations and provide a basis for engineering applications [37].

The prediction model combined with the energy management platform optimizes the control algorithm of electrical equipment by a mathematical model, and it is compared with domestic and international industries. For example, the China Urban Rail Transit Association statistically analyzed the annual energy consumption and passenger transport data of the national metro in 2019 according to the Evaluation Method of Energy Consumption and Emission Index of Urban Rail Transit, in which the average total energy consumption per person-kilometer of urban rail transit is $0.155 \mathrm{kWh}$, and the average total energy consumption per vehicle-kilometer is $4.19 \mathrm{kWh}$ [1]. Through forecasting and benchmarking, the energy consumption model is established, the energy consumption quota management system is implemented, and the energy management work is guided by the energy management platform. Finally, a better energy management and monitoring platform is provided for metro operation managers, so that many metro stations of different types can save energy and reduce emissions.

\section{Energy saving design of comprehensive power supply for metro weak current system}

A metro station is a type of public building, which is an important place for passengers to get on, get off, transfer and wait. In order to provide a safe, comfortable and sanitary environment for passengers, the station is generally composed of power supply, electromechanical and weak current systems, and the main energy consumption is electricity consumption. The weak current system of the station mainly ensures the safe operation of the station, and its energy consumption is affected by many factors including passenger satisfaction, station area, passenger flow and ambient temperature outside the station. Different factors affect the weak current power consumption of the station, and the analysis of their influence is helpful to clarify the energy consumption characteristics of the weak current system of the station. By collecting and learning the main influencing factors after analyzing the influencing factors, the energy management platform can estimate the future energy consumption demand of the metro, accurately predict the energy consumption needed during a certain period in the metro station, reduce the energy consumption of the metro station as much as possible while ensuring its reliable operation, and finally guide the station to manage energy and realize energy saving and emission reduction.

To predict the station energy consumption and provide the station energy consumption quota, it is necessary to adopt a prediction algorithm and increase the energy consumption meter. In this paper, firstly, an important factor analysis method is used to select the factors that have great influence on the energy consumption of the station, and based on this, a method for predicting the energy consumption quota of the weak current system equipment is put forward to achieve an energy-saving design of the weak current system equipment. This method can be extended to other energy-saving design scenarios. The specific process is shown in Fig. 4.

\subsection{Correlation analysis of energy consumption of the station weak current system}

The energy consumption data for the weak current system equipment in urban rail transit stations is characterized by different energy consumption ranges in different regions and different fluctuation of energy consumption in different weak current subsystems. The key problem is how to extract the characteristics of energy consumption data which have a great influence on the energy consumption of the weak current system equipment, and then to accurately predict the energy consumption of the weak current system equipment in the stations. There are many factors that affect the energy consumption of weak current systems in stations, but the degree of influence is different. This paper utilizes Pearson's correlation coefficient method to determine the characteristic parameters that have a significant impact on the energy consumption cost of weak current systems.

In statistics, Pearson's correlation coefficient method is used to measure the correlation degree (linear correlation) between two variables $\mathrm{X}$ and $\mathrm{Y}$, and its value is between -1 and 1 . The closer the Pearson value is to -1 , the stronger the negative correlation between the two variables; the closer the Pearson value is to 1 , the stronger the positive correlation between the two variables, and 0 indicates that the two variables have no correlation. The significance of Pearson's correlation coefficient method is used to measure whether the linear relationship between two variables is reliable, and its values represent different significant relationships between two variables in different ranges. When the significance value is less than or equal to 0.01 , it means that there is a very significant linear relationship between samples; when the significance value is between 0.01 and 0.05 , the linear relationship between samples is not significant.

Based on the existing data, through analysis and combining with the actual situation, this paper mainly analyzes 

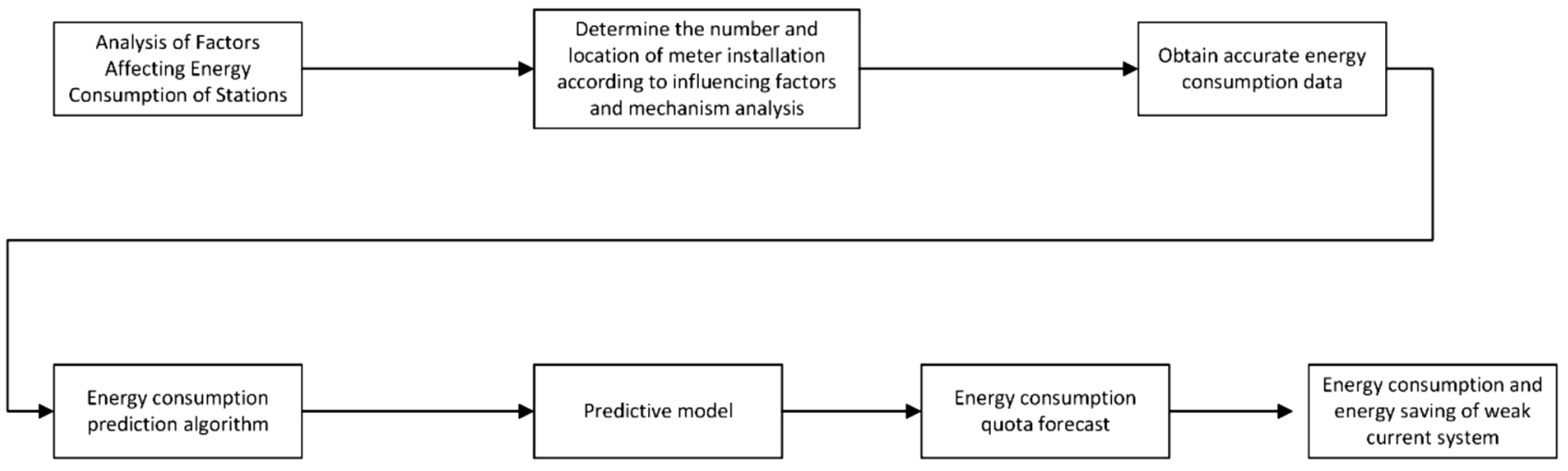

Fig. 4 Flow chart of energy consumption quota prediction and analysis of weak current system

from three aspects: influencing factors of station area, influencing factors of station passenger flow and influencing factors of various types of equipment quantity in the station weak current system. Pearson's correlation coefficient method is used to analyze the relationship between these different influencing factors and equipment energy consumption of the weak current system, and to determine the main influencing factors of energy consumption of the weak current system in stations. The correlation evaluation corresponding to correlation coefficient is shown in Table 4, and the specific result after analysis is shown in Table 5 .

As can be seen from Table 5, for different stations, the metro station floorage factor has the greatest correlation with the energy consumption of the weak current system and strong correlation with the equipment quantity, while the passenger flow factor has less influence. Therefore, when designing meters, we should consider the different station areas and the power of equipment to set up fourthlevel meters in order to achieve more detailed monitoring and quota prediction of energy consumption.

\subsection{Integration methods for the station weak current power supply system}

Through the correlation analysis of the energy consumption of the weak current system, the floorage has the greatest impact on energy consumption. Therefore, the power supply system needs to increase the metering of the weak current system equipment accordingly. However,

Table 4 Correlation coefficient and correlation analysis

\begin{tabular}{ll}
\hline r| value range & Correlation \\
\hline $0 \sim 0.1$ & Irrelevance \\
$0.1 \sim 0.3$ & Weak correlation \\
$0.3 \sim 0.5$ & Moderate correlation \\
$0.5 \sim 1$ & Strong correlation \\
\hline
\end{tabular}

considering that the traditional weak current system mainly purchases UPS from each system separately and sets different distribution boxes, it is impossible to set meters according to the region. At the same time, the discrete setting of UPS also has the problem of low load rate, resulting in high UPS configuration and inability to achieve the ideal energy efficiency value.

Based on the above problems, the method of power integration is proposed in order to ensure the power supply safety and reliability of the weak current system. The main principle of power integration is that the integrated power system shall meet the technical requirements of all integrated systems for power supply and ensure the reliable and safe operation of each system. The integration of the power supply system shall be calculated uniformly according to the load nature, capacity demand and standby time of each integrated system, to select the capacity of UPS and battery. In addition, monitoring requirements, overvoltage protection and grounding measures and requirements for ambient temperature shall also be considered.

In recent years, the domestic urban rail transit system has integrated the UPS system to varying degrees, and the integration mode and scope are different in different regions and different lines. The rapid development and maturity of control technology and high-capacity power supply systems provide a guarantee for the centralized integration of UPS in urban rail transit.

Based on this, this paper proposes to integrate all weak current system power supplies into an integrated power supply, and transform the traditional single system mode into a centralized $(1+1)$ parallel double-bus integrated power supply. The integrated power supply is provided by the lighting power design with two main power supplies, which are respectively supplied to two UPS hosts through two isolation transformers. The battery pack provides a backup power supply guarantee for the integrated power supply system. The UPS provides stable and reliable 
Table 5 Correlation analysis results of different influencing factors on energy consumption of the station weak current system

\begin{tabular}{|c|c|c|}
\hline Influencing factor & Pearson correlation & Significance \\
\hline Overall floorage & 0.68 & 0.00 \\
\hline Daily passenger flow at stations & 0.03 & 0.40 \\
\hline Number of speakers & 0.468653122 & 0.00 \\
\hline Number of gun cameras & 0.441902592 & 0.00 \\
\hline Number of couplers & 0.440634881 & 0.00 \\
\hline Number of antennas & 0.43128356 & 0.00 \\
\hline Number of face recognition cameras & 0.415766734 & 0.00 \\
\hline Number of multi-cameras & 0.372594962 & 0.00 \\
\hline Number of spherical cameras & 0.361793949 & 0.00 \\
\hline RRU (radio remote unit) quantity & 0.314185317 & 0.00 \\
\hline Number of LED displays & 0.273534866 & 0.00 \\
\hline Number of power dividers & 0.25600265 & 0.00 \\
\hline Number of pickups & 0.246291782 & 0.00 \\
\hline Number of directional antennas & 0.244541471 & 0.00 \\
\hline Number of trackside telephones & 0.223443818 & 0.00 \\
\hline Number of hemispheric cameras & 0.198430073 & 0.00 \\
\hline Tunnel AP number & 0.195918614 & 0.00 \\
\hline Number of switches & 0.188289858 & 0.00 \\
\hline Number of power amplifiers & 0.171662258 & 0.00 \\
\hline Number of single-sided digital sub-clocks & 0.166060505 & 0.00 \\
\hline Number of analog phones & 0.129409867 & 0.00 \\
\hline Number of station controllers & 0.083741738 & 0.00 \\
\hline Number of LCD displays & 0.083741738 & 0.00 \\
\hline Number of access layer switches & 0.036373609 & 0.02 \\
\hline Number of BBU (baseband processing units) & 0.0051698 & 0.74 \\
\hline Number of battery testers & -0.066839715 & 0.00 \\
\hline Number of wall-mounted analog phones & -0.092656182 & 0.00 \\
\hline Number of dispatching telephone extensions & -0.115706209 & 0.00 \\
\hline Number of IP phones & -0.166467112 & 0.00 \\
\hline Number of switches in convergence layer & -0.180750662 & 0.00 \\
\hline
\end{tabular}

uninterruptible power to the main distribution cabinet and lower distribution cabinet/box. Switches and meters are set in the main distribution cabinet and lower distribution cabinet according to the area, to achieve distinctive area measurement.

According to the functional area, the station can be divided into platform, station hall, transfer channel, and entrance and exit. The station hall is also divided into equipment and management room area and public area. Public areas are divided into paid areas and unpaid areas according to whether or not passengers pay. The platform is also divided into waiting area and equipment room area. The specific power system partition is shown in Fig. 5.

\subsection{Energy consumption prediction algorithm for the station weak current system}

Machine learning is used to predict the energy consumption of station weak current systems. In the application of machine learning, feature selection is usually an important step. For the actual model building, there are usually too many variables in the data set, and most of the variables have nothing to do with the target problem. There are several disadvantages to dealing with an excessively large feature set. One is that purely technical processing of large feature sets slows down the algorithm, takes up too many resources, and is very inconvenient. Another, more important issue is that when the number of variables is significantly higher than the optimal one, the accuracy of many machine learning algorithms will decrease. Among the many feature selection methods, the Boruta algorithm 


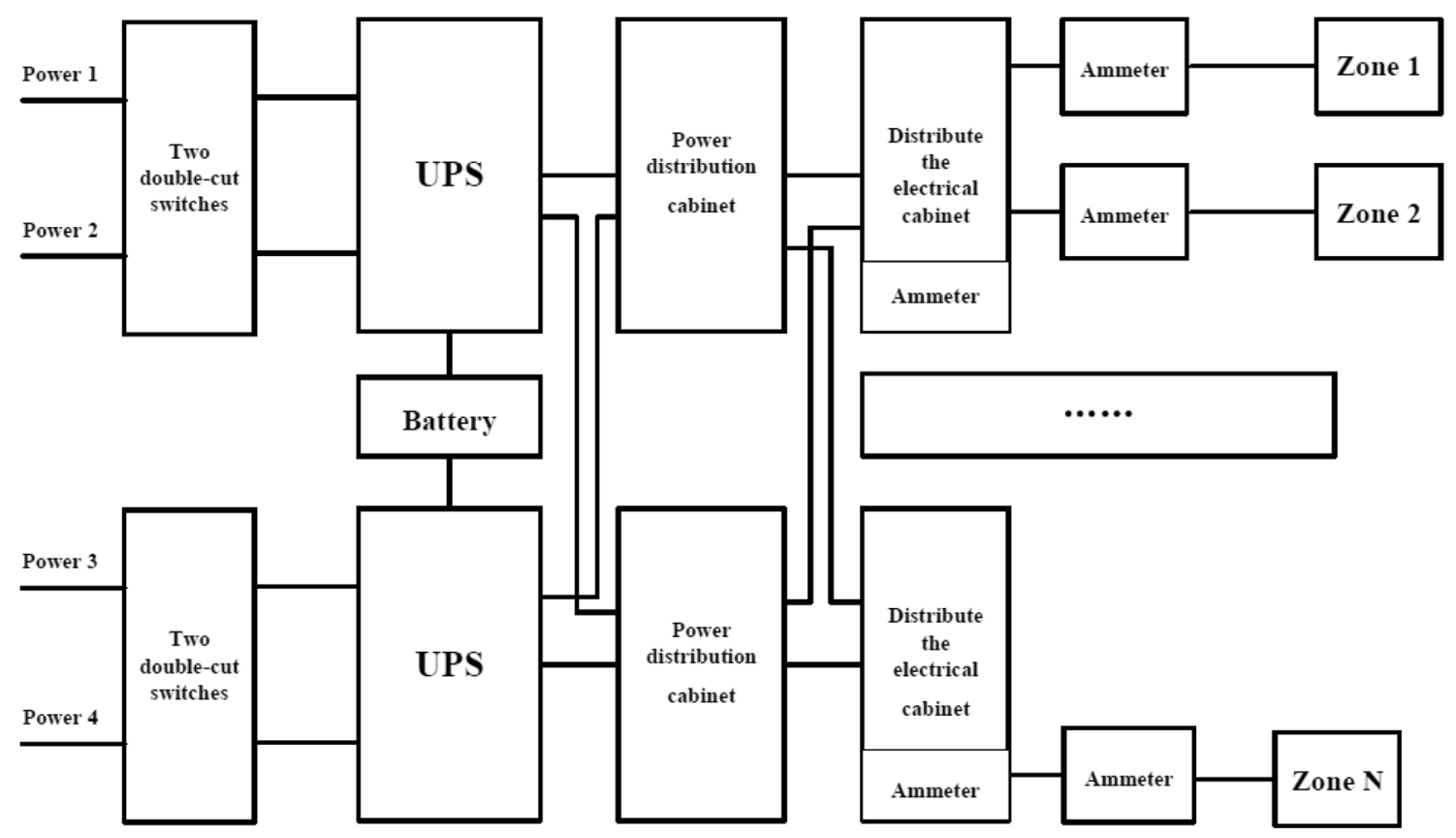

Fig. 5 Schematic diagram of integrated power supply system

is used to extract the feature data that have a large influence on the target value from the original feature data, and the PCA algorithm is used to fuse and reduce the dimensions of the extracted feature data that have a large influence on the target value, to obtain the feature data which can better reflect the important influence on the target value. As for the machine learning algorithm, boosting is a machine learning algorithm that can be used to reduce the deviation in supervised learning. It mainly obtains the sample subset by operating the sample set, and then trains a series of base classifiers on the sample subset using the weak classification algorithm. XGBoost is one such algorithm with a good application effect in numerical prediction, but its disadvantage is that it cannot predict high-dimensional data. According to the characteristics of the above three algorithms, this paper proposes a Boruta + PCA + XGBoost algorithm, which can accurately predict the energy consumption of equipment in the weak current system of stations. The specific algorithm flow is shown in Fig. 6. The algorithm is divided into two parts: model training and model calling. In the model training part, after Boruta feature screening and PCA feature fusion for dimension reduction, the $\mathrm{XGBoost}$ algorithm is used to train the model, and the model is deployed to production for interface calling. In the calling part, the data generated by production in turn go through the same process as in training, and finally the trained model is called to obtain the energy consumption prediction quota result.

\subsubsection{Boruta algorithm}

The Boruta algorithm is a wrapper method based on a random forest algorithm [38]. Random forest is an integrated method which performs classification by voting on multiple unbiased weak classifiers, such as a decision tree. A characteristic of the Boruta algorithm is that it can filter out all the feature sets that are related to the dependent variables, instead of only the feature sets that minimize the loss function of the current model. This helps us to screen

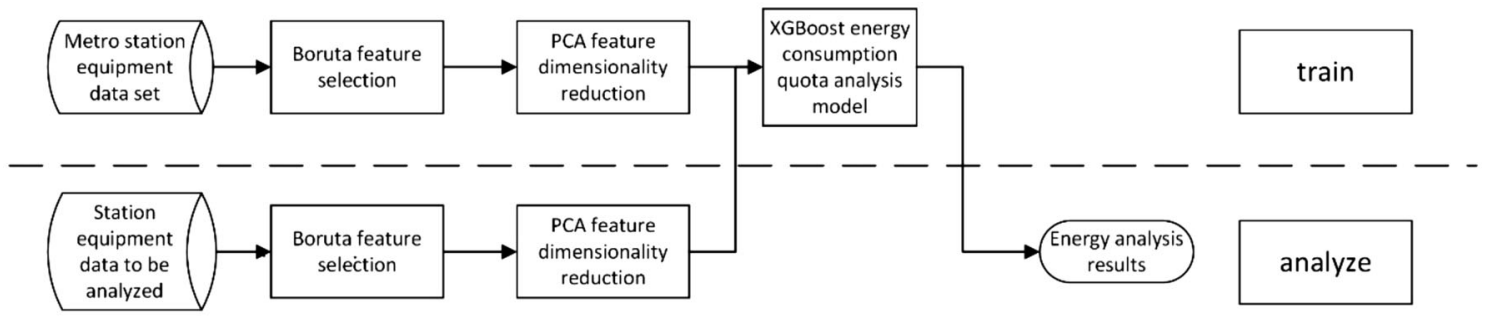

Fig. 6 Flowchart of Boruta + PCA + XGBoost algorithm 
out all the energy consumption-related feature data, delete redundant features and determine the best feature subset.

The basic idea of the Boruta algorithm is to evaluate the importance of each characteristic variable by a cyclic method. Firstly, the input original feature matrix $\mathrm{X}$ is randomly shuffled to obtain shadow features. Then, the input original feature matrix $\mathrm{X}$ is spliced with the obtained shadow features, and a new feature matrix $Y$ is obtained by random scrambling. The random forest classifier is run to calculate the $\mathrm{z}$-score of all features on the feature matrix $\mathrm{Y}$, as shown in Eq. 1. Then the maximum $\mathrm{Z}$-score among shadow attributes (MZSA) is compared with the $Z$-score of each feature of the original feature matrix $X$. When the $z-$ score of the feature of the original feature matrix $\mathrm{X}$ is far lower than MZSA, the feature is marked as unimportant. Reciprocating and cycling is performed until all features of the original feature matrix $\mathrm{X}$ have been assigned importance or the number of random forest iterations has been reached, and finally the best feature subset is obtained.

$\mathrm{Z}-$ scores $=\frac{Y_{i}-\overline{Y_{i}}}{S_{i}}$

Formula: $Y_{i}$ The $i$ th characteristic of the new characteristic matrix $Y$;

$\overline{Y_{i}}$ — The $i$ th eigenvalue average of the new eigenvalue matrix $Y$;

$S_{i}-$ The $i$ th characteristic standard value of the new characteristic matrix $Y$.
The specific flow of the Boruta algorithm is shown in Fig. 7. Firstly, we input the related feature matrix $X$ of energy consumption quota model and shuffle each feature value of $X$ to get shadow features. Then, $X$ and shadow features are spliced to form a new feature matrix $Y$, and a random forest classifier is run on $Y$ to calculate the $z$-score of each feature of $Y$. Then we find the largest $z$-score in shadow features, and mark it as MZSA. We compare the $z$ score of each feature in $X$ with it, and delete the features whose $z$-scores are significantly smaller than MZSA. We repeat the above process until all the features left by $X$ are marked as important.

\subsubsection{PCA algorithm}

The PCA algorithm is a multivariate statistical method. It is one of the most commonly used dimensionality reduction methods. It transforms a set of potentially correlated variable data into a set of linearly uncorrelated variables through orthogonal transformation. The transformed variable is called the principal component [39].

The optimization goal of the PCA problem is to reduce a set of an n-dimensional vector matrix $X$ to $k$-dimensional ( 0 $<k<n$ ), and the goal is to select $k$ unit orthogonal bases so that after the original data are transformed to this set of bases, the covariance between each feature is 0 , and the variance of the feature is as large as possible; the largest $k$ variances are taken under the constraint of orthogonality.
Fig. 7 Flow chart of the Boruta algorithm

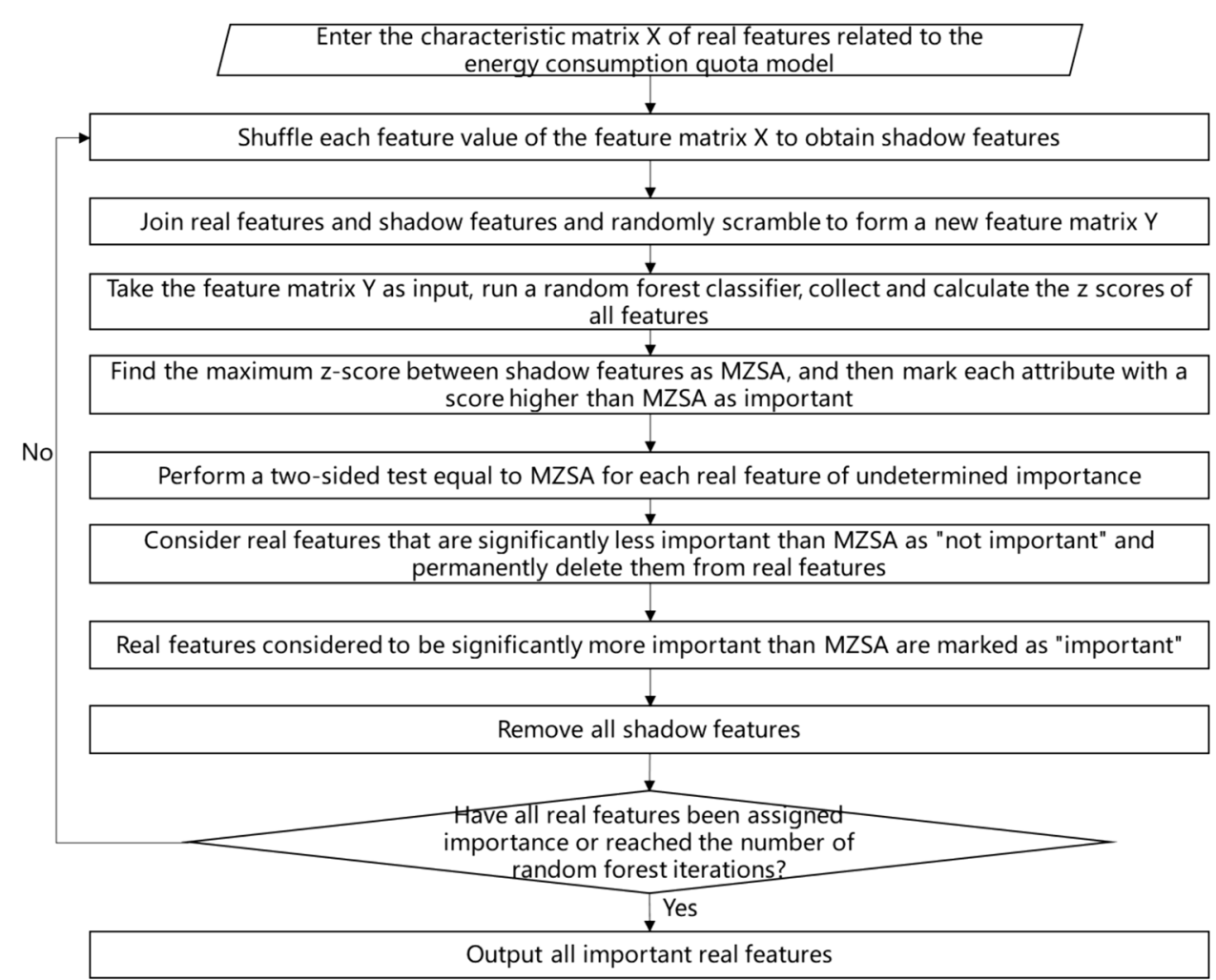


Fig. 8 PCA algorithm flow chart

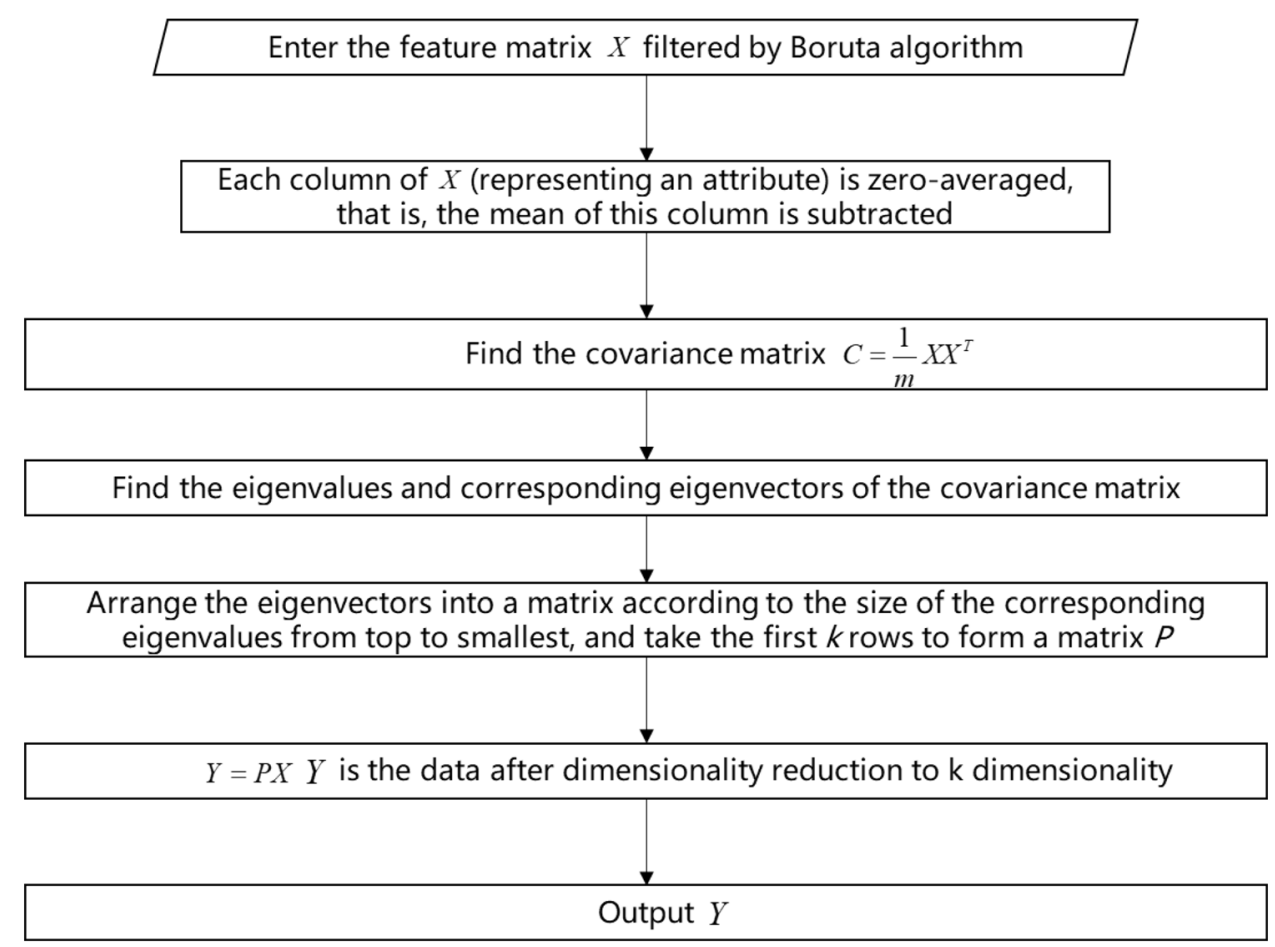

The flow of the PCA algorithm is shown in Fig. 8. At first, the feature matrix $X$ filtered by the Boruta algorithm in the previous step is input, and the covariance matrix $C$ of the matrix $X$ after zero averaging is calculated. Then we calculate the eigenvalues of $C$ and the corresponding eigenvectors, arrange the eigenvectors into a matrix according to the eigenvalues from large to small, and take the first $k$ rows of matrix $P$. At last, $P$ and $X$ after zero averaging are multiplied by matrix, and the final resulting matrix $Y$ reduced to $k$ dimensions is obtained.

\subsubsection{XGBoost algorithm}

The XGBoost algorithm is an integrated learning method based on a classification and regression tree (CART) [40]. Unlike the random forest that gives each decision tree the same voting weight, the generation of the next decision tree in the XGBoost algorithm is related to the training and prediction of the previous decision tree (by training the previous decision tree with a lower accuracy and giving the samples higher learning weights to improve the accuracy of the model). Compared with other ensemble learning algorithms, XGBoost on the one hand improves the robustness of the model by introducing regular terms and column sampling, and on the other hand, it adopts a parallelization strategy when each tree selects the split point, thereby greatly improving the operation speed of this model.
XGBoost is an additive model composed of multiple base models. If the tree model to be trained in the $t$ th iteration is $f_{t}(x)$, then:

$\hat{y}_{i}^{(t)}=\sum_{k=1}^{t} f_{x}\left(x_{i}\right)=\hat{y}_{i}^{(t-1)}+f_{t}\left(x_{i}\right)$,

where $\hat{y}_{i}^{(t)}$ represents the prediction result of energy consumption sample $i$ after the $t$ th iteration, and $f_{t}\left(x_{i}\right)$ is the model of the $t$ th tree. The objective function of XGBoost is defined as follows:

$\mathrm{Obj}=\sum_{i=1}^{n} l\left(y_{i}, \hat{y}_{i}\right)+\sum_{i=1}^{t} \Omega\left(f_{i}\right)$,

where $\sum^{t} \Omega\left(f_{i}\right)$ is to sum the complexity of all $t$ trees and add the $\overline{\mathrm{m}}^{1}$ to the objective function as a regularization term to prevent over fitting of the model. $\sum_{i=1}^{n} l\left(y_{i}, \hat{y}_{i}\right)$ is the loss function.

Then, according to the forward step-by-step algorithm, in step $t$, the predicted value of the model for the $i$ th sample is:

$\hat{y}_{i}^{(t)}=\hat{y}_{i}^{(t-1)}+f_{t}\left(x_{i}\right)$

Among them, $f_{t}\left(x_{i}\right)$ is the predicted value of the residual between the predicted value $\hat{y}_{i}^{(t-1)}$ and the real value in fitting step $t-1$. XGBoost fits the residual through continuous iteration. When the set maximum tree model depth is reached, the iteration is stopped. 


\section{Implementation of an integrated power supply system for the weak current system of Kunming Rail Transit Line 4}

Kunming Rail Transit Line 4 is a rapid rail transit line connecting Kunming's main urban area and Chenggong New District. Kunming Metro Line 4 passes through Wuhua District, High-tech Zone, Panlong District, Guandu District, Economic Development Zone and Chenggong New District, with high-density passenger flow along the line, which is of great significance and has a role in solving the urban traffic problems in Kunming and driving the development along Line 4.

Kunming Metro Line 4 starts from Chenjiaying Station in the northwest of Kunming's main city and ends at Kunming South Railway Station in Chenggong New Town. The route diagram of Kunming Rail Transit Line 4 is shown in Fig. 9. The total length of Line 4 is $43.396 \mathrm{~km}$, the elevated line is $3.491 \mathrm{~km}$, the ground line and $\mathrm{U}$-shaped trough-section are $0.781 \mathrm{~km}$, and the underground line is $39.124 \mathrm{~km}$. There are 29 stations in total along Line 4, including three elevated stations, 26 underground stations and 14 transfer stations. Line 4 has a depot at Dayantian and two parking lots, Guangwei parking lot and Bailongtan parking lot. The three main substations are the North Railway Station, Maju and Dounan main substations, among which a new Maju main substation is built.

The weak current system design of Kunming Rail Transit Line 4 breaks the traditional framework of the weak current system and adopts a new system reconstructed by deeply integrating 21 weak current subsystems. The cloudbased rail intelligent automation system (CRIAS for short) adopts innovative fusion architecture, which completely replaces the chimney architecture of the traditional weak current system. Traditional weak current systems such as integrated monitoring systems, automatic train monitoring systems, broadcasting systems, passenger information systems, centralized alarm systems, automatic fare collection systems, platform doors, and communication systems will only exist in name, but in fact they are no longer independent. Its infrastructure layer, data acquisition layer, data processing layer and application layer are all integrated into the new overall architecture. The system weakens the system division of labor, strengthens professional functions, and places more emphasis on serving metro operations and passengers. It provides basic support for the innovation of management mode and the reform of maintenance management mechanisms of operating enterprises, realizes green energy saving, reduces staff and increases efficiency, and finally realizes smart metro.

\subsection{The integrated power supply system of Rail Transit Line 4 of Kunming}

The integrated power supply equipment in the CRIAS is responsible for providing uninterrupted power supply to the weak current systems in the station and depot, including the automatic monitoring of communication and signal systems, automatic fire alarm systems, environment and equipment monitoring systems, power monitoring systems, access control, automatic fare collection systems and platform doors.

The integrated power supply system adopts the centralized $(1+1)$ parallel double-bus mode, so it is equipped with two sets of independent UPS systems, which are completely independent from the UPS host to the general distribution cabinet, then to the distribution cabinet, and finally to the load end. Two sets of independent power supply are provided to weak current equipment with a dual power supply. For equipment with a single power supply, an STS static switch is used, which can also realize the function of a dual independent power supply. One threephase total power meter is installed in the general distribution cabinet as a third-level meter for station energy measurement to realize the energy consumption measurement of the whole weak current system; branch power supply circuits are separated according to the equipment installation area, and a single electrical energy meter is installed as the fourth-level meter of station energy measurement in order to obtain itemized measurement according to the section and equipment.

The power network management terminal of the control center realizes the centralized monitoring and management of the operation information, status and energy consumption of the power system equipment of the whole line, including UPS, battery pack and general distribution cabinet. The operation status information, fault information and alarm information of the power supply equipment of each station are sent to the control center for unified processing through the transmission system. The network communication between the power supply system and the transmission system adopts the Ethernet ring network mode to ensure that the whole network will not be affected by the fault of single-point network equipment. After the UPS, battery pack and general distribution cabinet at each station are networked, they are uniformly uploaded to the platform transmission system through the Ethernet port of the general distribution cabinet.

\subsection{Design of backup power supply for the stations' weak current system}

The integrated power supply system of the station is integrated according to the integrated monitoring system 
(including environment and equipment monitoring, automatic fire alarm system and access control system), special communication (including telephones, clocks, CCTV, PIS, $\mathrm{PA}$, transmission and other systems), automatic fare collection (including gates, automatic ticket vending machines, ceiling guidance signs and other equipment), and office automation (including office computers and other equipment in the ticket office and station master's room), and the nature of the power consumption and power demand of depot/parking lot security is designed and calculated to select the UPS and battery capacity.

According to the integration scope, the power load of the electrical equipment for all systems in the station is calculated. The specific statistics are shown in Table 6.

According to the requirements of Uninterruptible Power Systems for Communication (UPS) (YD/T 1095-2008), the formula for calculating the output active power of the UPS equipment is shown in Eq. 5.

Output active power $=$ Rated capacity $\times 0.7 \mathrm{~kW} / \mathrm{kVA}$
Therefore, according to the calculation of the above company, the rated capacity of the configured UPS is $54.652 / 0.7 \mathrm{~kW} / \mathrm{kVA}=78.036 \mathrm{kVA}$. Combined with the selection of product specifications and models, the rated capacity of the UPS selected for the station is $80 \mathrm{kVA}$.

\subsection{Design of station integrated power meters}

The UPS system of the station machine room mainly supplies power for regular loads such as intelligent control all-in-one machines, intelligent control units, switches and terminal operation display screens, and impact loads such as access control and fare collection machines. Each station will design different distribution boxes and power supply circuits according to the quantity, type and installation area of electrical equipment.

Based on the quantity and power of electric equipment in the station, each station of Kunming Line 4 is equipped with two UPS $(80 \mathrm{kVA})$, two isolation transformers $(80 \mathrm{kVA})$, two sets of battery packs (64 for each set, 128 in
Fig. 9 Route diagram of Kunming Rail Transit Line 4

\section{Basic situation of Kunming Rail Transit Planning line 4 project}

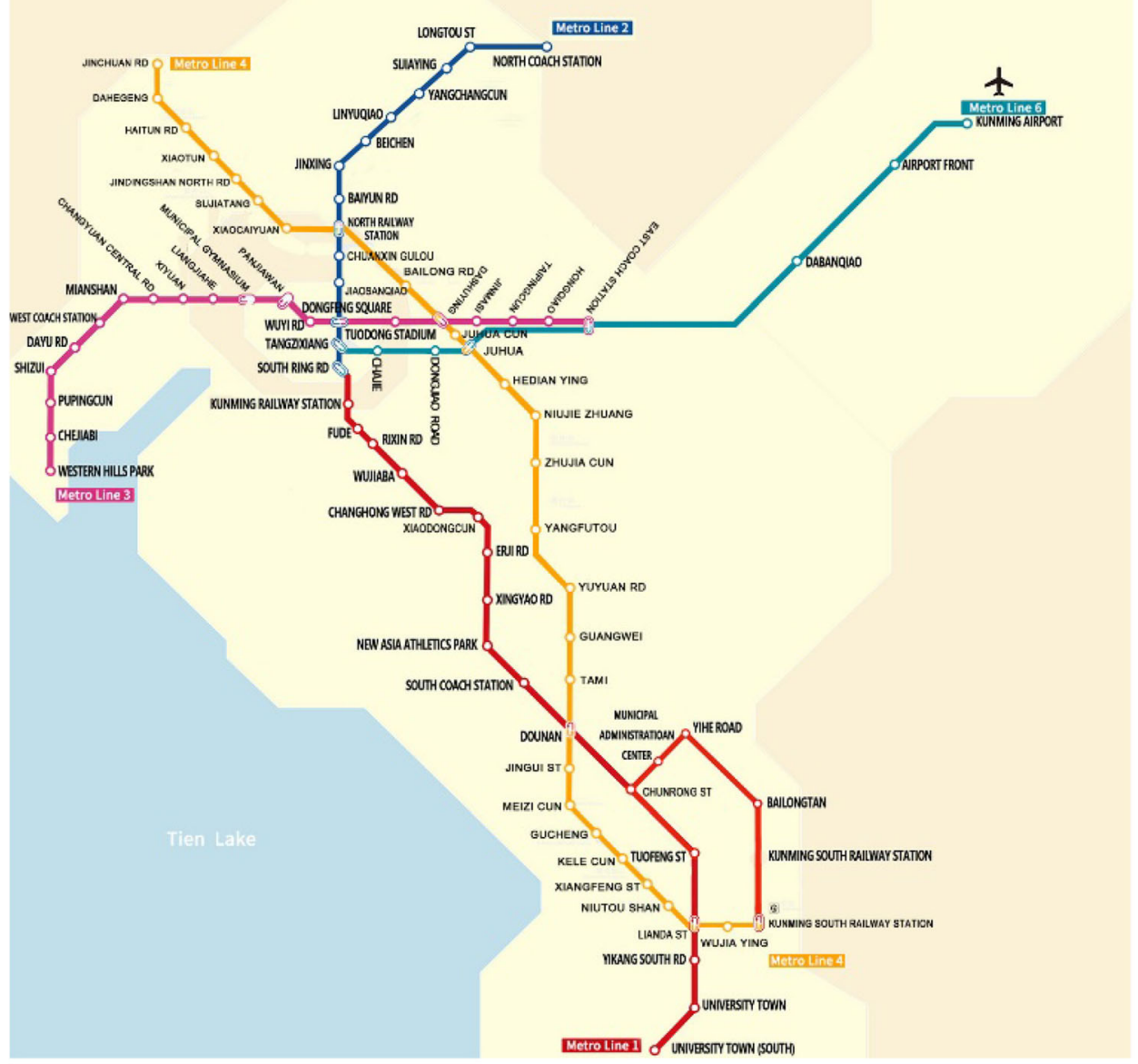


total, 77AH for each battery), two sets of battery monitoring systems, two sets of general distribution cabinets, four sets of sub-distribution cabinets (12 STS are set in each distribution cabinet) and one power network management unit.

An energy meter is set in the general distribution cabinet, and a general meter is set in each general distribution cabinet, which belong to level 3 measurement. Other meters are set to measure the power consumption of different equipment and regions, which belong to level 4 measurement. The power circuit and meter distribution are shown in Tables 7, 8, 9 and 10 .

After the power supply circuit and meter are designed in combination with the power supply equipment and power, the station UPS system is designed. The station integrated power monitoring system collects the operation and status data of the equipment to the intelligent control integrated machine through the PLC collector set in the station power distribution cabinet, and then transmits it to the central power monitoring system through the transmission network. The specific structural diagram is shown in Fig. 10.

In the specific electrical design process, the three-phase watt-hour meter monitoring of the power parameters of the incoming circuit in the main distribution cabinet is connected to the terminals of the RS485 expansion card of PLC1 by a MODBUS protocol through its own RS485 interface. The feeder shunt watt-hour meter of the main distribution cabinet also has an RS485 interface, and 21 shunt watt-hour meters are also connected to the bus of the RS485 expansion card of PLC1. The wiring diagrams of the two main distribution cabinets are shown in Figs. 11, 12 and 13. The wiring diagrams of all electric meters are shown in Figs. 12 and 14.

\subsection{Integrated power supply monitoring and measurement data acquisition}

In the design scheme of the metro weak current power system, in order to realize remote centralized monitoring of all power equipment, all equipment has an intelligent communication interface through which the running status of power equipment, status information, fault information, alarm information and energy metering information for power equipment in each station can be collected in real time.

Specifically, PLCs are used in two independent main distribution cabinets of each station or parking lot to realize the collection and processing of various data, and the measured data and status are displayed through a 7-inch color touchscreen. The operating parameters of voltage, current, frequency, power factor, active power, reactive power and power degree of the input circuit and each output circuit can be accurately measured by configuring a high-precision watt-hour meter for each circuit, and the state data of each switch state, arrester state and timesharing power-down state can be monitored at the same time.

In the monitoring system of the distribution cabinet, historical curves and alarm data can be recorded, and realtime alarms can be given for various abnormal phenomena. In the central power supply monitoring system, various real-time data, historical curves and alarm data of the station can be recorded, and real-time alarms can be issued for various abnormal phenomena. The specific system interface is shown in Fig. 15.

\subsection{Energy consumption data acquisition and prediction}

The integrated power system platform collects various energy consumption data in real time and pushes the data to the big data platform. The big data platform analyzes and learns the energy consumption data of each station. The specific daily energy consumption of the station from October 2020 to March 2021 is shown in Figs. 16 and 17.

Figures 16 and 17 show that with the change in time, the change trend of electrical energy is relatively stable, and the power consumption is approximately a fixed value with little change. In the process of energy management, energy measurement is the basis of formulating scientific and reasonable energy consumption limit standards [41]. Reasonable energy consumption quota should be based on energy measurement data. In order to ensure the accuracy and validity of the measurement data, through the accumulation and value mining of energy measurement data,

Table 6 Load statistics of Jinchuan road station integration system

\begin{tabular}{lll}
\hline Serial number & Major & Load $(\mathrm{kW})$ \\
\hline 1 & Official telephone & 1.2 \\
2 & Private telephone & 1 \\
3 & Information network & 0.1 \\
4 & Bearing network & 1.2 \\
5 & Dedicated wireless & 2 \\
6 & CCTV & 2.725 \\
7 & PA & 4.8 \\
8 & CLK & 0.6 \\
9 & PSCADA & 0.3 \\
10 & COMPS & 4 \\
11 & PIS & 4.4 \\
12 & ACS & 2 \\
13 & BAS & 5 \\
14 & ATS & 5.3 \\
15 & AFC & 20 \\
Total & & 54.625 \\
\hline
\end{tabular}


Table 7 System diagram of distribution cabinet \#1

\begin{tabular}{|c|c|c|c|c|}
\hline \multicolumn{2}{|c|}{ Comprehensive power supply room } & \multicolumn{2}{|c|}{ Communication equipment room } & \multirow[t]{2}{*}{ Remarks } \\
\hline $\begin{array}{l}\text { Power distribution } \\
\text { cabinet }\end{array}$ & $\begin{array}{l}\text { Electric } \\
\text { meter }\end{array}$ & Distribution cabinet & Power supply equipment & \\
\hline $\begin{array}{l}\text { General distribution } \\
\text { cabinet } 1\end{array}$ & PJ01 & Distribution cabinet $1-1$ & $\begin{array}{l}\text { Broadcast cabinet } \\
\text { Special telephone cabinet } \\
\text { Clock cabinet } \\
\text { All-in-one machine cabinet \#1 } \\
\text { Clock cabinet OA } \\
\text { Transmission cabinet (integrated carrier network) } \\
\text { Wireless cabinet } \\
\text { Clock cabinet (equal protection equipment) } \\
\text { Service telephone }\end{array}$ & $\begin{array}{l}\text { Dual power supply } \\
\text { equipment }\end{array}$ \\
\hline $\begin{array}{l}\text { General distribution } \\
\text { cabinet } 1\end{array}$ & PJ08 & Distribution cabinet $1-2$ & BAS/access control cabinet \#1 & $\begin{array}{l}\text { Dual power supply } \\
\text { equipment }\end{array}$ \\
\hline $\begin{array}{l}\text { General distribution } \\
\text { cabinet } 1\end{array}$ & PJ02 & Distribution cabinet $1-3$ & Signal equipment & $\begin{array}{l}\text { Dual power supply } \\
\text { equipment }\end{array}$ \\
\hline $\begin{array}{l}\text { General distribution } \\
\text { cabinet } 1\end{array}$ & PJ10 & $\begin{array}{l}\text { Distribution cabinet } 1-4 \\
\quad \text { (main) }\end{array}$ & $\begin{array}{l}\text { Power supply } 1 \text { of IBP panel in vehicle control } \\
\text { room } \\
\text { Comprehensive monitoring equipment room } \\
\text { power supply } \\
\text { Comprehensive distribution cabinet } \\
\text { PIS-entrance LED no. } 1 \text { road } \\
\text { PIS-entrance LED no. } 2 \text { road } \\
\text { PIS-AP antenna (small uplink mileage) } \\
\text { CCTV-camera no. } 1 \text { road (entrance) } \\
\text { CCTV-camera no. } 2 \text { road (entrance) } \\
\text { CCTV-camera no. } 3 \text { road } \\
\text { CCTV-camera 4/standby }\end{array}$ & $\begin{array}{l}\text { Single power supply } \\
\text { equipment }\end{array}$ \\
\hline $\begin{array}{l}\text { General distribution } \\
\quad \text { cabinet } 2\end{array}$ & PJ10 & $\begin{array}{l}\text { Distribution cabinet } 1-5 \\
\quad \text { (standby) }\end{array}$ & $\begin{array}{l}\text { Power supply } 1 \text { of IBP panel in vehicle control room } \\
\text { Comprehensive monitoring equipment room } \\
\text { power supply } \\
\text { Comprehensive distribution cabinet } \\
\text { PIS-entrance LED no. } 1 \text { road } \\
\text { PIS-entrance LED no. } 2 \text { road } \\
\text { PIS-AP antenna (small uplink mileage) } \\
\text { CCTV-Camera no. } 1 \text { road (entrance) } \\
\text { CCTV-camera no. } 2 \text { road (entrance) } \\
\text { CCTV-camera no. } 3 \text { road } \\
\text { CCTV-camera 4/standby }\end{array}$ & $\begin{array}{l}\text { Single power supply } \\
\text { equipment }\end{array}$ \\
\hline $\begin{array}{l}\text { General distribution } \\
\text { cabinet } 1\end{array}$ & PJ11 & $\begin{array}{l}\text { Distribution cabinet 1-6 } \\
\text { (main) }\end{array}$ & $\begin{array}{l}\text { AFC-ticket office power supply } 1 \text { (computer, } \\
\text { printer) } \\
\text { AFC-ticket office power supply } 2 \text { (note machine, } \\
\text { coin machine) } \\
\text { AFC-maintenance room power supply/standby } \\
\text { PIS-AP antenna (small downlink mileage) } \\
\text { PIS-station hall LCD no. } 1 \text { road } \\
\text { PIS-station hall LCD } 2 \text { nd road/standby } \\
\text { CCTV-camera no. } 9 \text { road } \\
\text { CCTV-camera no. } 10 \text { road } \\
\text { CCTV-camera no. } 11 / \text { standby } \\
\text { AFC-clock cabinet (AFC panic button box) }\end{array}$ & $\begin{array}{l}\text { Single power supply } \\
\text { equipment }\end{array}$ \\
\hline
\end{tabular}


Table 7 continued

\begin{tabular}{|c|c|c|c|c|}
\hline \multicolumn{2}{|c|}{ Comprehensive power supply room } & \multicolumn{2}{|c|}{ Communication equipment room } & \multirow[t]{2}{*}{ Remarks } \\
\hline $\begin{array}{l}\text { Power distribution } \\
\text { cabinet }\end{array}$ & $\begin{array}{l}\text { Electric } \\
\text { meter }\end{array}$ & Distribution cabinet & Power supply equipment & \\
\hline $\begin{array}{l}\text { General distribution } \\
\text { cabinet } 2\end{array}$ & PJ11 & $\begin{array}{l}\text { Distribution cabinet 1-7 } \\
\quad \text { (standby) }\end{array}$ & $\begin{array}{l}\text { AFC-ticket office power supply } 1 \text { (computer, } \\
\text { printer) } \\
\text { AFC-ticket office power supply } 2 \text { (note machine, } \\
\text { coin machine) } \\
\text { AFC-maintenance room power supply/standby } \\
\text { PIS-AP antenna (small downlink mileage) } \\
\text { PIS-station hall LCD no. } 1 \text { road } \\
\text { PIS-station hall LCD } 2 \text { nd road/standby } \\
\text { CCTV-camera no. } 9 \text { road } \\
\text { CCTV-camera no. } 10 \mathrm{road} \\
\text { CCTV-camera no. } 11 / \text { standby } \\
\text { AFC-clock cabinet (AFC panic button box) }\end{array}$ & $\begin{array}{l}\text { Single power supply } \\
\text { equipment }\end{array}$ \\
\hline $\begin{array}{l}\text { General distribution } \\
\text { cabinet } 1\end{array}$ & PJ17 & $\begin{array}{l}\text { Distribution cabinet } 1-8 \\
\quad \text { (main) }\end{array}$ & $\begin{array}{l}\text { AFC-power supply } 1 \text { (entrance gate) } \\
\text { AFC-power supply } 2 \text { (entrance gate) } \\
\text { AFC-power supply } 3 \text { (entrance gate/ticket } \\
\text { vending machine) } \\
\text { AFC-power supply } 4 \text { (entrance gate/ticket } \\
\text { vending machine) } \\
\text { AFC-power supply } 5 \text { (ticket vending machine) } \\
\text { AFC-power supply } 6 \text { (ticket vending } \\
\text { machine/standby) } \\
\text { AFC-power supply } 7 \text { (ceiling guide sign) } \\
\text { AFC-power supply } 8 \text { (switch) } \\
\text { AFC-power supply } 9 \text { (switch/standby) } \\
\text { AFC-power supply } 10 \text { (standby) }\end{array}$ & $\begin{array}{l}\text { Single power supply } \\
\text { equipment }\end{array}$ \\
\hline $\begin{array}{l}\text { General distribution } \\
\text { cabinet } 2\end{array}$ & PJ17 & $\begin{array}{l}\text { Distribution cabinet 1-9 } \\
\quad \text { (standby) }\end{array}$ & $\begin{array}{l}\text { AFC-power supply } 1 \text { (entrance gate) } \\
\text { AFC-power supply } 2 \text { (entrance gate) } \\
\text { AFC-power supply } 3 \text { (entrance gate/ticket } \\
\text { vending machine) } \\
\text { AFC-power supply } 4 \text { (entrance gate/ticket } \\
\text { vending machine) } \\
\text { AFC-power supply } 5 \text { (ticket vending machine) } \\
\text { AFC-power supply } 6 \text { (ticket vending } \\
\text { machine/standby) } \\
\text { AFC-power supply } 7 \text { (ceiling guide sign) } \\
\text { AFC-power supply } 8 \text { (switch) } \\
\text { AFC-power supply } 9 \text { (switch/standby) } \\
\text { AFC-power supply } 10 \text { (standby) }\end{array}$ & $\begin{array}{l}\text { Single power supply } \\
\text { equipment }\end{array}$ \\
\hline
\end{tabular}

the energy consumption quota of energy-consuming equipment is given by a machine learning method. The energy consumption quota method based on machine learning involves taking a large number of statistical samples as the object, obtaining the energy consumption quota table by establishing a machine learning model, and then selecting the appropriate quota level to determine the energy consumption quota value according to the actual situation [42]. By analyzing the energy consumption data for each station along Kunming Metro Line 4, the average and median energy consumption of each station are obtained, as shown in Figs. 18 and19.

Through the data analysis of each station, it can be seen that the energy consumption of different stations varies greatly. Different stations need to be classified separately, and the station energy consumption quota cannot be formulated in a one-size-fits-all and average way, which would lead to a lack of fairness and rationality of the quota. 
Table 8 System diagram of distribution cabinet \#2

\begin{tabular}{|c|c|c|c|c|}
\hline \multicolumn{2}{|c|}{ Comprehensive power supply room } & \multicolumn{2}{|c|}{ Communication equipment room } & \multirow{2}{*}{$\begin{array}{l}\text { Remarks } \\
\text { Electric meter }\end{array}$} \\
\hline $\begin{array}{l}\text { Power distribution } \\
\text { cabinet }\end{array}$ & $\begin{array}{l}\text { Electric } \\
\text { meter }\end{array}$ & Distribution cabinet & Power distribution cabinet & \\
\hline $\begin{array}{l}\text { General distribution } \\
\quad \text { cabinet } 2\end{array}$ & PJ01 & Distribution cabinet 2-1 & $\begin{array}{l}\text { Broadcast cabinet } \\
\text { Special telephone cabinet } \\
\text { Clock cabinet } \\
\text { All-in-one machine cabinet \#1 } \\
\text { Clock cabinet OA } \\
\text { Transmission cabinet (integrated carrier } \\
\text { network) } \\
\text { Wireless cabinet } \\
\text { Clock cabinet (equal protection equipment) } \\
\text { Service telephone }\end{array}$ & $\begin{array}{l}\text { Dual power supply } \\
\text { equipment }\end{array}$ \\
\hline $\begin{array}{l}\text { General distribution } \\
\quad \text { cabinet } 2\end{array}$ & PJ08 & Distribution cabinet 2-2 & BAS/access control cabinet \#1 & $\begin{array}{l}\text { Dual power supply } \\
\text { equipment }\end{array}$ \\
\hline $\begin{array}{l}\text { General distribution } \\
\quad \text { cabinet } 2\end{array}$ & PJ02 & Distribution cabinet $2-3$ & Signal equipment & $\begin{array}{l}\text { Dual power supply } \\
\text { equipment }\end{array}$ \\
\hline $\begin{array}{l}\text { General distribution } \\
\text { cabinet } 1\end{array}$ & PJ12 & $\begin{array}{l}\text { Distribution cabinet } 2-4 \\
\text { (standby) }\end{array}$ & $\begin{array}{l}\text { IBP panel power supply } 2 \text { in vehicle control } \\
\text { room } \\
\text { Main office power supply } \\
\text { PIS-AP antenna (small uplink mileage) } \\
\text { PIS-entrance LED no. } 3 \text { road } \\
\text { PIS-entrance LED no. } 4 \text { road } \\
\text { CCTV-camera no. } 5 \text { road (entrance) } \\
\text { CCTV-camera no. } 6 \text { road (entrance) } \\
\text { CCTV-camera no. } 7 \text { road } \\
\text { CCTV-camera no. } 8 / \text { standby }\end{array}$ & $\begin{array}{l}\text { Single power supply } \\
\text { equipment }\end{array}$ \\
\hline $\begin{array}{l}\text { General distribution } \\
\quad \text { cabinet } 2\end{array}$ & PJ12 & $\begin{array}{l}\text { Distribution cabinet 2-5 } \\
\quad \text { (main) }\end{array}$ & $\begin{array}{l}\text { IBP panel power supply } 2 \text { in vehicle control } \\
\text { room } \\
\text { Main office power supply } \\
\text { PIS-AP antenna (small uplink mileage) } \\
\text { PIS-entrance LED no. } 3 \text { road } \\
\text { PIS-entrance LED no. } 4 \text { road } \\
\text { CCTV-camera no. } 5 \text { road (entrance) } \\
\text { CCTV-camera no. } 6 \text { road (entrance) } \\
\text { CCTV-camera no. } 7 \text { road } \\
\text { CCTV-camera no. } 8 / \text { standby }\end{array}$ & $\begin{array}{l}\text { Single power supply } \\
\text { equipment }\end{array}$ \\
\hline $\begin{array}{l}\text { General distribution } \\
\text { cabinet } 1\end{array}$ & PJ04 & $\begin{array}{l}\text { Distribution cabinet 2-6 } \\
\text { (standby) }\end{array}$ & $\begin{array}{l}\text { BAS/entrance guard cabinet (entrance guard } \\
\text { controller) } \\
\text { BAS/access control cabinet (access control } \\
\text { power supply) } \\
\text { PIS-AP antenna } \\
\text { PIS-station hall LCD no. } 3 \text { road } \\
\text { PIS-station hall LCD road 4/standby } \\
\text { CCTV-camera no. } 12 \text { road } \\
\text { CCTV-camera no. } 13 \text { road } \\
\text { CCTV-camera no. } 14 / \text { standby } \\
\text { CCTV-camera no. } 15 / \text { standby }\end{array}$ & $\begin{array}{l}\text { Single power supply } \\
\text { equipment }\end{array}$ \\
\hline
\end{tabular}


Table 8 continued

\begin{tabular}{|c|c|c|c|c|}
\hline \multicolumn{2}{|c|}{ Comprehensive power supply room } & \multicolumn{2}{|c|}{ Communication equipment room } & \multirow{2}{*}{$\begin{array}{l}\text { Remarks } \\
\text { Electric meter }\end{array}$} \\
\hline $\begin{array}{l}\text { Power distribution } \\
\text { cabinet }\end{array}$ & $\begin{array}{l}\text { Electric } \\
\text { meter }\end{array}$ & Distribution cabinet & Power distribution cabinet & \\
\hline $\begin{array}{l}\text { General distribution } \\
\text { cabinet } 2\end{array}$ & PJ04 & $\begin{array}{l}\text { Distribution cabinet 2-7 } \\
\quad \text { (main) }\end{array}$ & $\begin{array}{l}\text { BAS/entrance guard cabinet (entrance guard } \\
\text { controller) } \\
\text { BAS/access control cabinet (access control } \\
\text { power supply) } \\
\text { PIS-AP antenna } \\
\text { PIS-station hall LCD no. } 3 \text { road } \\
\text { PIS-station hall LCD road } 4 / \text { standby } \\
\text { CCTV-camera no. } 12 \text { road } \\
\text { CCTV-camera no. } 13 \text { road } \\
\text { CCTV-camera no. } 14 / \text { standby } \\
\text { CCTV-camera no. } 15 / \text { standby }\end{array}$ & $\begin{array}{l}\text { Single power supply } \\
\text { equipment }\end{array}$ \\
\hline $\begin{array}{l}\text { General distribution } \\
\text { cabinet } 1\end{array}$ & PJ18 & $\begin{array}{l}\text { Distribution cabinet 2-8 } \\
\text { (standby) }\end{array}$ & $\begin{array}{l}\text { AFC-power supply } 1 \text { (outbound gate) } \\
\text { AFC-power supply } 2 \text { (outbound gate) } \\
\text { AFC-power supply } 3 \text { (outbound gate) } \\
\text { AFC-power supply } 4 \text { (exit gate/ticket vending } \\
\text { machine) } \\
\text { AFC-power supply } 5 \text { (ticket vending machine) } \\
\text { AFC-power supply } 6 \text { (semi-automatic ticket } \\
\text { vending machine) } \\
\text { AFC-power supply } 7 \text { (ceiling guide sign) } \\
\text { AFC-power supply } 8 \text { (switch) } \\
\text { AFC-power supply } 9 \text { (switch/standby) } \\
\text { AFC-power supply } 10 \text { (standby) }\end{array}$ & $\begin{array}{l}\text { Single power supply } \\
\text { equipment }\end{array}$ \\
\hline $\begin{array}{l}\text { General distribution } \\
\quad \text { cabinet } 2\end{array}$ & PJ18 & $\begin{array}{l}\text { Distribution cabinet 2-9 } \\
\quad \text { (main) }\end{array}$ & $\begin{array}{l}\text { AFC-power supply } 1 \text { (outbound gate) } \\
\text { AFC-power supply } 2 \text { (outbound gate) } \\
\text { AFC-power supply } 3 \text { (outbound gate) } \\
\text { AFC-power supply } 4 \text { (exit gate/ticket vending } \\
\text { machine) } \\
\text { AFC-power supply } 5 \text { (ticket vending machine) } \\
\text { AFC-power supply } 6 \text { (semi-automatic ticket } \\
\text { vending machine) } \\
\text { AFC-power supply } 7 \text { (ceiling guide sign) } \\
\text { AFC-power supply } 8 \text { (switch) } \\
\text { AFC-power supply } 9 \text { (switch/standby) } \\
\text { AFC-power supply } 10 \text { (standby) }\end{array}$ & $\begin{array}{l}\text { Single power supply } \\
\text { equipment }\end{array}$ \\
\hline
\end{tabular}

After the overall analysis of the station weak current system, the energy consumption quota data are given using the Boruta + PCA + XGBoost algorithm, and the results are shown in Fig. 20.

Figure 20 shows that the Boruta + PCA + XGBoost algorithm can better predict the energy consumption data for Jinchuan Road station. The specific results are shown in Table 11.

\subsection{Energy consumption data monitoring and early warning}

In addition to energy consumption determination through big data analysis and machine learning, the integrated power system platform also analyzes the operation of the equipment and the measurement data for each itemized meter. It is found that some data deviate from the actual energy consumption design, such as the data of the PJ17 meter in the distribution cabinet, which measures energy consumption data 24 hours a day for four gates, one ticket 
Table 9 System diagram of distribution cabinet \#3

\begin{tabular}{|c|c|c|c|c|}
\hline \multicolumn{2}{|c|}{ Comprehensive power supply room } & \multicolumn{2}{|c|}{ Communication equipment room } & \multirow[t]{2}{*}{ Remarks electric meter } \\
\hline $\begin{array}{l}\text { Power distribution } \\
\text { cabinet }\end{array}$ & $\begin{array}{l}\text { Electric } \\
\text { meter }\end{array}$ & Distribution cabinet & Power distribution cabinet & \\
\hline $\begin{array}{l}\text { General distribution } \\
\text { cabinet } 1\end{array}$ & PJ05 & Distribution cabinet $3-1$ & Intelligent integrated machine cabinet \#2 & $\begin{array}{l}\text { Dual power supply } \\
\text { equipment }\end{array}$ \\
\hline $\begin{array}{l}\text { General distribution } \\
\text { cabinet } 2\end{array}$ & PJ05 & Distribution cabinet $3-2$ & Intelligent integrated machine cabinet \#2 & $\begin{array}{l}\text { Dual power supply } \\
\text { equipment }\end{array}$ \\
\hline $\begin{array}{l}\text { General distribution } \\
\text { cabinet } 1\end{array}$ & PJ19 & $\begin{array}{l}\text { Distribution cabinet 3-3 } \\
\quad \text { (main) }\end{array}$ & $\begin{array}{l}\text { BAS/entrance guard cabinet (entrance guard } \\
\text { controller) \#2 } \\
\text { PIS-entrance LED no. } 1 \text { road } \\
\text { PIS-entrance LED no. } 2 \text { road } \\
\text { PIS-station hall LCD no. } 1 \text { road } \\
\text { PIS-station hall LCD } 2 \text { nd road/standby } \\
\text { CCTV-camera no. } 1 \text { road } \\
\text { CCTV-camera road } 2 \\
\text { CCTV-camera no. } 3 \text { road } \\
\text { CCTV-camera } 4 / \text { standby } \\
\text { CCTV-camera no. } 5 / \text { standby }\end{array}$ & $\begin{array}{l}\text { Single power supply } \\
\text { equipment }\end{array}$ \\
\hline $\begin{array}{l}\text { General distribution } \\
\text { cabinet } 2\end{array}$ & PJ19 & $\begin{array}{l}\text { Distribution cabinet 3-4 } \\
\quad \text { (standby) }\end{array}$ & $\begin{array}{l}\text { BAS/entrance guard cabinet (entrance guard } \\
\text { controller) \#2 } \\
\text { PIS-entrance LED no. } 1 \text { road } \\
\text { PIS-entrance LED no. } 2 \text { road } \\
\text { PIS-station hall LCD no. } 1 \text { road } \\
\text { PIS-station hall LCD } 2 \text { nd road/standby } \\
\text { CCTV-camera no. } 1 \text { road } \\
\text { CCTV-camera road } 2 \\
\text { CCTV-camera no. } 3 \text { road } \\
\text { CCTV-camera } 4 / \text { standby } \\
\text { CCTV-camera no. } 5 / \text { standby }\end{array}$ & $\begin{array}{l}\text { Single power supply } \\
\text { equipment }\end{array}$ \\
\hline $\begin{array}{l}\text { General distribution } \\
\text { cabinet } 1\end{array}$ & PJ06 & $\begin{array}{l}\text { Distribution cabinet 3-5 } \\
\text { (standby) }\end{array}$ & $\begin{array}{l}\text { BAS/access control cabinet (Access control } \\
\text { power supply) \#2 } \\
\text { PIS-entrance LED no. } 3 \text { road } \\
\text { PIS-entrance LED no. } 4 \text { road } \\
\text { PIS-station hall LCD no. } 3 \text { road } \\
\text { PIS-station hall LCD road } 4 / \text { standby } \\
\text { CCTV-camera no. } 6 \text { road } \\
\text { CCTV-camera no. } 7 \text { road } \\
\text { CCTV-camera no. } 8 \text { road } \\
\text { CCTV-camera no. } 9 / \text { standby } \\
\text { CCTV-camera no. } 10 / \text { standby }\end{array}$ & $\begin{array}{l}\text { Single power supply } \\
\text { equipment }\end{array}$ \\
\hline $\begin{array}{l}\text { General distribution } \\
\text { cabinet } 2\end{array}$ & PJ06 & $\begin{array}{l}\text { Distribution cabinet 3-6 } \\
\text { (main) }\end{array}$ & $\begin{array}{l}\text { BAS/access control cabinet (access control } \\
\text { power supply) \#2 } \\
\text { PIS-entrance LED no. } 3 \text { road } \\
\text { PIS-entrance LED no. } 4 \text { road } \\
\text { PIS-station hall LCD no. } 3 \text { road } \\
\text { PIS-station hall LCD road } 4 / \text { standby } \\
\text { CCTV-camera no. } 6 \text { road } \\
\text { CCTV-camera no. } 7 \text { road } \\
\text { CCTV-camera no } .8 \text { road } \\
\text { CCTV-camera no. } 9 / \text { standby } \\
\text { CCTV-camera no. } 10 / \text { standby }\end{array}$ & $\begin{array}{l}\text { Single power supply } \\
\text { equipment }\end{array}$ \\
\hline
\end{tabular}


Table 9 continued

\begin{tabular}{|c|c|c|c|c|}
\hline \multicolumn{2}{|c|}{ Comprehensive power supply room } & \multicolumn{2}{|c|}{ Communication equipment room } & \multirow[t]{2}{*}{ Remarks electric meter } \\
\hline $\begin{array}{l}\text { Power distribution } \\
\text { cabinet }\end{array}$ & $\begin{array}{l}\text { Electric } \\
\text { meter }\end{array}$ & Distribution cabinet & Power distribution cabinet & \\
\hline $\begin{array}{l}\text { General distribution } \\
\text { cabinet } 1\end{array}$ & PJ09 & $\begin{array}{l}\text { Distribution cabinet 3-7 } \\
\text { (main) }\end{array}$ & $\begin{array}{l}\text { AFC-power supply } 1 \text { (entrance gate) } \\
\text { AFC-power supply } 2 \text { (entrance gate) } \\
\text { AFC-power supply } 3 \text { (entrance gate/ticket } \\
\text { vending machine) } \\
\text { AFC-power supply } 4 \text { (entrance gate/ticket } \\
\text { vending machine) } \\
\text { AFC-power supply } 5 \text { (ticket vending machine) } \\
\text { AFC-power supply } 6 \text { (ticket vending } \\
\text { machine/standby) } \\
\text { AFC-power supply } 7 \text { (ceiling guide sign) } \\
\text { AFC-power supply } 8 \text { (switch) } \\
\text { AFC-power supply } 9 \text { (switch/standby) } \\
\text { AFC-power supply } 10 \text { (standby) }\end{array}$ & $\begin{array}{l}\text { Single power supply } \\
\text { equipment }\end{array}$ \\
\hline $\begin{array}{l}\text { General distribution } \\
\text { cabinet } 2\end{array}$ & PJ09 & $\begin{array}{l}\text { Distribution cabinets } 3-8 \\
\text { (standby) }\end{array}$ & $\begin{array}{l}\text { AFC-power supply } 1 \text { (entrance gate) } \\
\text { AFC-power supply } 2 \text { (entrance gate) } \\
\text { AFC-power supply } 3 \text { (entrance gate/ticket } \\
\text { vending machine) } \\
\text { AFC-power supply } 4 \text { (entrance gate/ticket } \\
\text { vending machine) } \\
\text { AFC-power supply } 5 \text { (ticket vending machine) } \\
\text { AFC-power supply } 6 \text { (ticket vending } \\
\text { machine/standby) } \\
\text { AFC-power supply } 7 \text { (ceiling guide sign) } \\
\text { AFC-power supply } 8 \text { (switch) } \\
\text { AFC-power supply } 9 \text { (switch/standby) } \\
\text { AFC-power supply } 10 \text { (standby) }\end{array}$ & $\begin{array}{l}\text { Single power supply } \\
\text { equipment }\end{array}$ \\
\hline $\begin{array}{l}\text { General distribution } \\
\text { cabinet } 1\end{array}$ & PJ20 & $\begin{array}{l}\text { Distribution cabinets 3-9 } \\
\text { (standby) }\end{array}$ & $\begin{array}{l}\text { AFC-power supply } 1 \text { (outbound gate) } \\
\text { AFC-power supply } 2 \text { (outbound gate) } \\
\text { AFC-power supply } 3 \text { (outbound gate) } \\
\text { AFC-power supply } 4 \text { (exit gate/ticket vending } \\
\text { machine) } \\
\text { AFC-power supply } 5 \text { (ticket vending machine) } \\
\text { AFC-power supply } 6 \text { (semi-automatic ticket } \\
\text { vending machine) } \\
\text { AFC-power supply } 7 \text { (ceiling guide sign) } \\
\text { AFC-power supply } 8 \text { (switch) } \\
\text { AFC-power supply } 9 \text { (switch/standby) } \\
\text { AFC-power supply } 10 \text { (standby) }\end{array}$ & $\begin{array}{l}\text { Single power supply } \\
\text { equipment }\end{array}$ \\
\hline $\begin{array}{l}\text { General distribution } \\
\text { cabinet } 2\end{array}$ & PJ20 & $\begin{array}{l}\text { Distribution cabinet 3-10 } \\
\quad \text { (main) }\end{array}$ & $\begin{array}{l}\text { AFC-power supply } 1 \text { (outbound gate) } \\
\text { AFC-power supply } 2 \text { (outbound gate) } \\
\text { AFC-power supply } 3 \text { (outbound gate) } \\
\text { AFC-power supply } 4 \text { (exit gate/ticket vending } \\
\text { machine) } \\
\text { AFC-power supply } 5 \text { (ticket vending machine) } \\
\text { AFC-power supply } 6 \text { (semi-automatic ticket } \\
\text { vending machine) } \\
\text { AFC-power supply } 7 \text { (ceiling guide sign) } \\
\text { AFC-power supply } 8 \text { (switch) }\end{array}$ & $\begin{array}{l}\text { Single power supply } \\
\text { equipment }\end{array}$ \\
\hline
\end{tabular}


Table 9 continued

\begin{tabular}{|c|c|c|c|c|}
\hline \multicolumn{2}{|c|}{ Comprehensive power supply room } & \multicolumn{2}{|c|}{ Communication equipment room } & \multirow[t]{2}{*}{ Remarks electric meter } \\
\hline $\begin{array}{l}\text { Power distribution } \\
\text { cabinet }\end{array}$ & $\begin{array}{l}\text { Electric } \\
\text { meter }\end{array}$ & Distribution cabinet & Power distribution cabinet & \\
\hline & & & AFC-power supply 9 (switch/standby) & \\
\hline & & & AFC-power supply 10 (standby) & \\
\hline $\begin{array}{l}\text { General distribution } \\
\text { cabinet } 1\end{array}$ & PJ03 & Distribution cabinet 3-11 & BAS/access control cabinet \#2 & Dual power supply equipment \\
\hline $\begin{array}{l}\text { General distribution } \\
\text { cabinet } 2\end{array}$ & PJ03 & Distribution cabinet 3-12 & BAS/access control cabinet \#2 & Dual power supply equipment \\
\hline
\end{tabular}

machine, the ceiling guide sign and one switch equipment, as shown in Fig. 21.

According to Fig. 21, in combination with the operation of the equipment, the equipment is generally in normal operation in the station, and can be in standby mode when it is shut down at night to reduce energy consumption. Through data monitoring, it is found that the energy consumption of the equipment during shutdown and no shutdown are basically the same. When the normal gate and ticket machine are shut down, the equipment will be in energy-saving and standby mode. For the gate, the power consumption is $150 \mathrm{~W}$ in the normal operation mode and $50 \mathrm{~W}$ in the standby mode. In this way, the energy-saving operation can be realized by monitoring to ensure that the field equipment complies with the design. The ideal energy consumption curve is shown in Fig. 22 if the energy-saving operation of the gate equipment is in standby mode during shutdown.

Through the real-time monitoring of the system and the analysis of energy consumption measurement data, the unreasonable phenomena in the energy consumption link are found and reported to the energy consumption management unit in real time. Now, the weak current maintenance center has checked the equipment-setting problems and asked the equipment manufacturer to put forward solutions. The energy-saving ratio is calculated based on "energy-saving ratio = energy-saving value of starting standby mode after hypothetical shutdown/energy consumption value of not enabling standby mode".

Finally, through calculation, if the standby mode transformation is started after the gate is stopped, gate energy consumption savings of $27.59 \%$ can be achieved.

According to the actual power consumption and energy consumption of each station, an energy consumption quota can be selected. With the energy consumption quota, the weak current system of the station is monitored according to the approved energy consumption quota. At the same time, we should establish and improve the quota management, reward and punishment system, and finally achieve energy conservation and consumption reduction.
Therefore, the metro company must strengthen the use of energy measurement data, must integrate, analyze and record the data measured by professional energy measuring instruments, and carry out reasonable and effective management of the measurement results in order to guide the production links, promptly detect problems and mistakes, strengthen the potential of energy conservation and reduced consumption, and maximize the interests of the enterprise [42].

\section{Conclusion}

Energy consumption in metro system has become a serious burden for metro operation companies. To achieve energy saving on metro weak current system, we conducted an indepth research and analysis on metro energy load classification and energy management, focusing in particular on the design and usage of power supply systems for metro weak current electromechanical systems. To make it clear how the energy consumption among the weak current system, based on the characteristics of the power supply system of the metro weak current system, we propose a series of measurements to monitor and predict energy consumption of the weak current system. In Kunming Metro Line 4, a comprehensive power supply design of the weak current system is carried out to reduce the number of UPS and improve the UPS utilization rate. In the distribution cabinet, different meters are set for the loop according to different areas and equipment conditions to meet the requirements of graded measurement of metro energy consumption. At the same time, the station energy consumption is predicted through the Boruta +PCA +XGBoost algorithm, and a reasonable energy consumption quota is given to ensure that "data originates from measurement and management depends on data".

By the application of graded metering of station power consumption, the station energy consumption is predicted, and the supervision of equipment energy consumption is realized. Based on the overall integration of cloud 
Table 10 System diagram of 4\# distribution cabinet

\begin{tabular}{|c|c|c|c|c|}
\hline \multicolumn{2}{|c|}{ Comprehensive power supply room } & \multicolumn{2}{|c|}{ Communication equipment room } & \multirow[t]{2}{*}{ Remarks electric meter } \\
\hline Power distribution cabinet & $\begin{array}{l}\text { Electric } \\
\text { meter }\end{array}$ & Distribution cabinet & Power distribution cabinet & \\
\hline $\begin{array}{l}\text { General distribution } \\
\text { cabinet } 1\end{array}$ & PJ16 & Distribution cabinet $4-1$ & $\begin{array}{l}\text { 3\# Intelligent integrated machine } \\
\text { cabinet } \\
\text { PSCADA cabinet }\end{array}$ & $\begin{array}{l}\text { Dual power supply } \\
\text { equipment }\end{array}$ \\
\hline $\begin{array}{l}\text { General distribution } \\
\text { cabinet } 2\end{array}$ & PJ16 & Distribution cabinet $4-2$ & $\begin{array}{l}\text { 3\# Intelligent integrated machine } \\
\text { cabinet } \\
\text { PSCADA cabinet }\end{array}$ & $\begin{array}{l}\text { Dual power supply } \\
\text { equipment }\end{array}$ \\
\hline $\begin{array}{l}\text { General distribution } \\
\text { cabinet } 1\end{array}$ & PJ14 & $\begin{array}{l}\text { Distribution cabinet 4-3 } \\
\text { (standby) }\end{array}$ & $\begin{array}{l}\text { ATS-departure timer } 1 \\
\text { ATS-departure timer } 3 / \text { standby } \\
\text { PIS-platform LCD road } 1 \\
\text { PIS-platform LCD road } 2 \\
\text { PIS-platform LCD road } 3 \\
\text { PIS-platform LCD road } 4 \\
\text { CCTV-camera no. } 1 \text { road } \\
\text { CCTV-camera road } 2 \\
\text { CCTV-camera no. 3/standby } \\
\text { CCTV-camera 4/standby } \\
\text { CCTV-platform monitor }\end{array}$ & $\begin{array}{l}\text { Single power supply } \\
\text { equipment }\end{array}$ \\
\hline $\begin{array}{l}\text { General distribution } \\
\text { cabinet } 2\end{array}$ & PJ14 & $\begin{array}{l}\text { Distribution cabinet 4-4 } \\
\quad \text { (main) }\end{array}$ & $\begin{array}{l}\text { ATS-departure timer } 1 \\
\text { ATS-departure timer } 3 / \text { standby } \\
\text { PIS-platform LCD road } 1 \\
\text { PIS-platform LCD road } 2 \\
\text { PIS-platform LCD road } 3 \\
\text { PIS-platform LCD road } 4 \\
\text { CCTV-camera no. } 1 \text { road } \\
\text { CCTV-camera road } 2 \\
\text { CCTV-camera no. 3/standby } \\
\text { CCTV-camera 4/standby } \\
\text { CCTV-platform monitor }\end{array}$ & $\begin{array}{l}\text { Single power supply } \\
\text { equipment }\end{array}$ \\
\hline $\begin{array}{l}\text { General distribution } \\
\text { cabinet } 1\end{array}$ & PJ13 & $\begin{array}{l}\text { Distribution cabinet } 4-5 \\
\quad \text { (main) }\end{array}$ & $\begin{array}{l}\text { ATS-departure timer } 2 \\
\text { ATS-departure timer } 4 / \text { standby } \\
\text { PIS-platform LCD road } 5 \\
\text { PIS-platform LCD road } 6 \\
\text { PIS-platform LCD road } 7 \\
\text { PIS-platform LCD road } 8 \\
\text { CCTV-camera no. } 5 \text { road } \\
\text { CCTV-camera no. } 6 \text { road } \\
\text { CCTV-camera no. } 7 / \text { standby } \\
\text { CCTV-camera no. 8/standby } \\
\text { CCTV-platform monitor }\end{array}$ & $\begin{array}{l}\text { Single power supply } \\
\text { equipment }\end{array}$ \\
\hline
\end{tabular}


Table 10 continued

\begin{tabular}{|c|c|c|c|c|}
\hline \multicolumn{2}{|c|}{ Comprehensive power supply room } & \multicolumn{2}{|c|}{ Communication equipment room } & \multirow[t]{2}{*}{ Remarks electric meter } \\
\hline Power distribution cabinet & $\begin{array}{l}\text { Electric } \\
\text { meter }\end{array}$ & Distribution cabinet & Power distribution cabinet & \\
\hline $\begin{array}{l}\text { General distribution cabinet } \\
\quad 2\end{array}$ & PJ13 & $\begin{array}{l}\text { Distribution cabinet } 4-6 \\
\text { (standby) }\end{array}$ & $\begin{array}{l}\text { ATS-departure timer } 2 \\
\text { ATS-departure timer } \\
\text { 4/standby } \\
\text { PIS-platform LCD road } 5 \\
\text { PIS-platform LCD road } 6 \\
\text { PIS-platform LCD road } 7 \\
\text { PIS-platform LCD road } 8 \\
\text { CCTV-camera no. } 5 \text { road } \\
\text { CCTV-camera no. } 6 \text { road } \\
\text { CCTV-camera no. 7/standby } \\
\text { CCTV-camera no. 8/standby } \\
\text { CCTV-platform monitor }\end{array}$ & $\begin{array}{l}\text { Single power supply } \\
\text { equipment }\end{array}$ \\
\hline
\end{tabular}

Fig. 10 Structure diagram of the station integrated power supply monitoring system

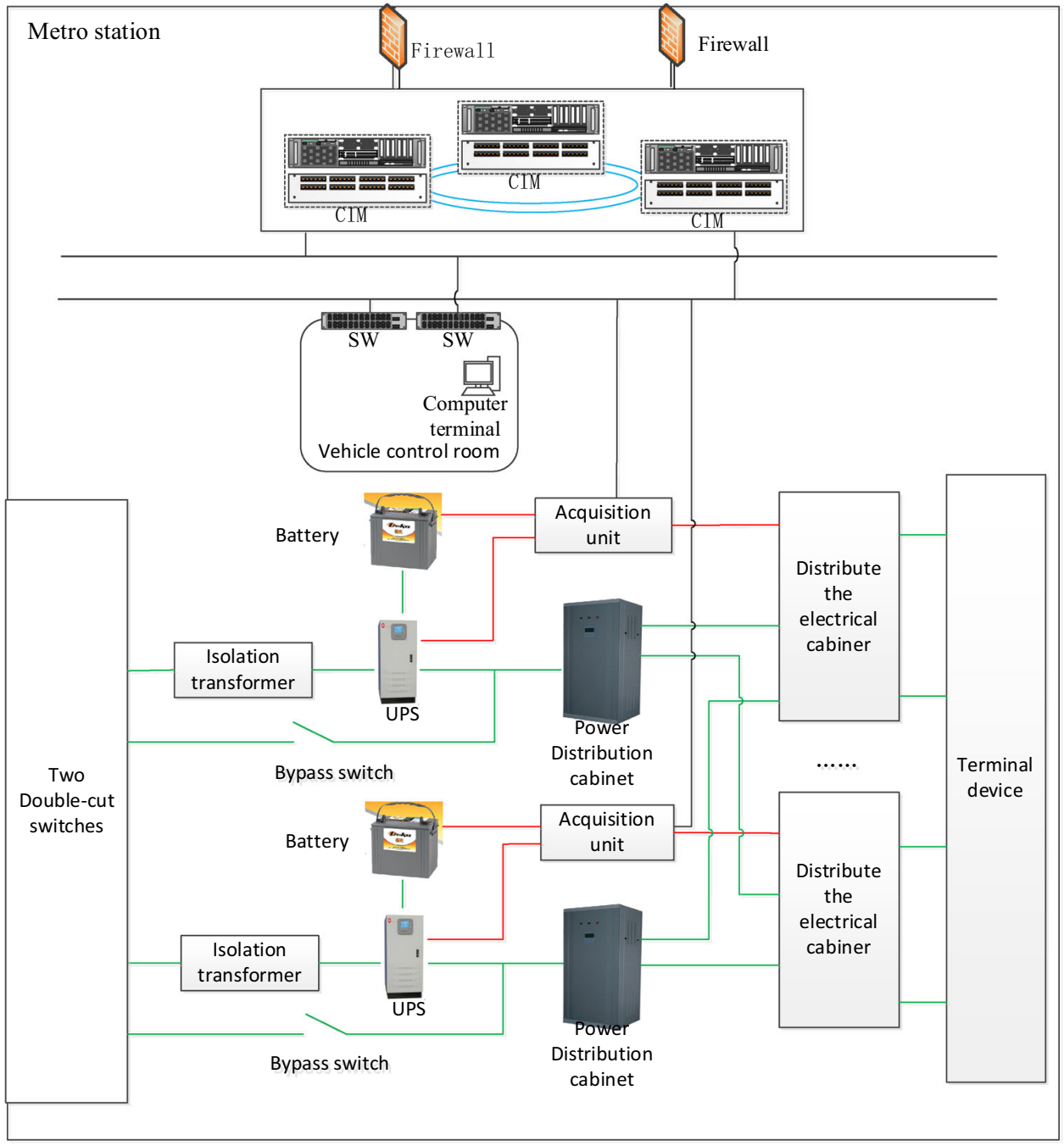




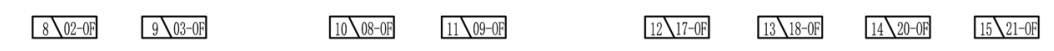
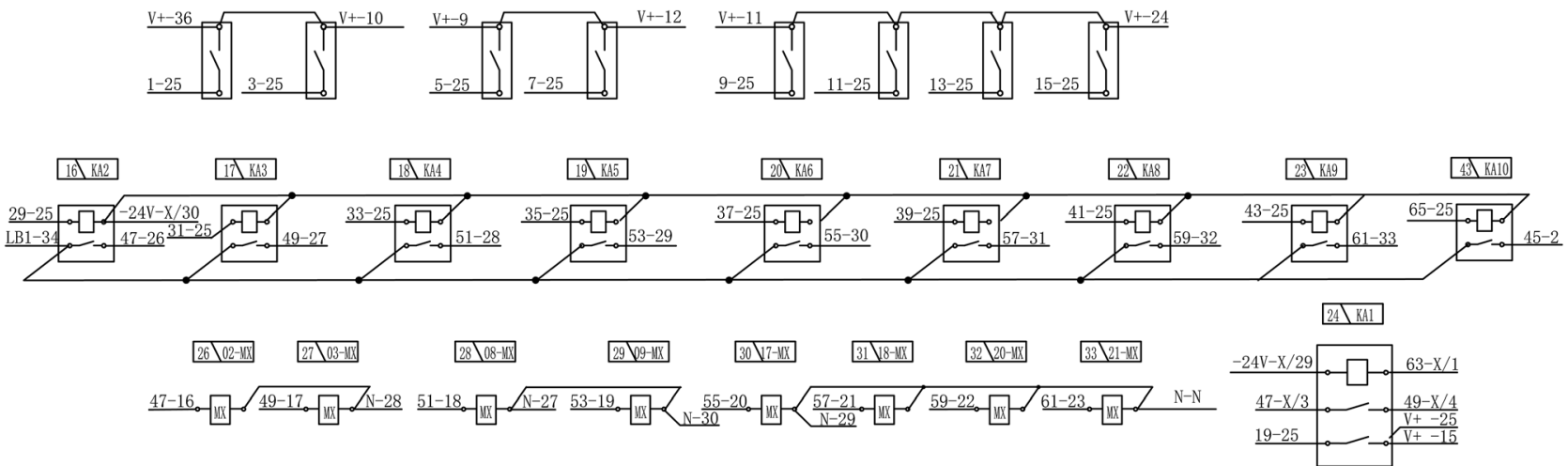

\begin{tabular}{|l|l|}
\hline 7 \\
\hline
\end{tabular}

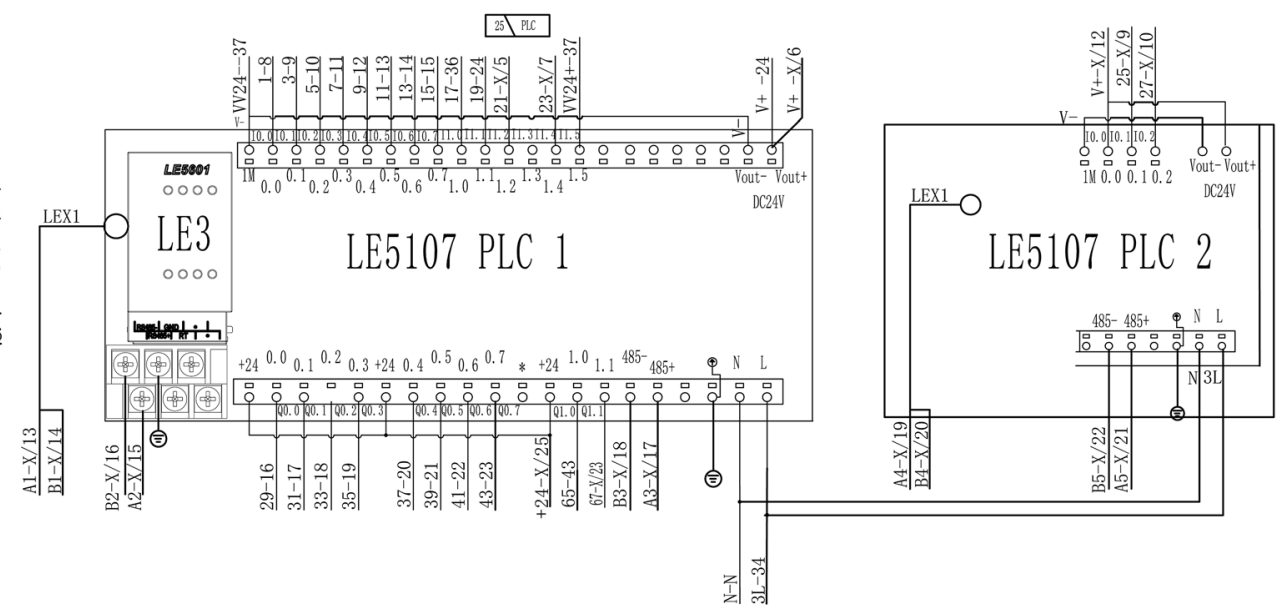

Fig. 11 Wiring diagram of general cabinet 1 of the Jinchuan Road station
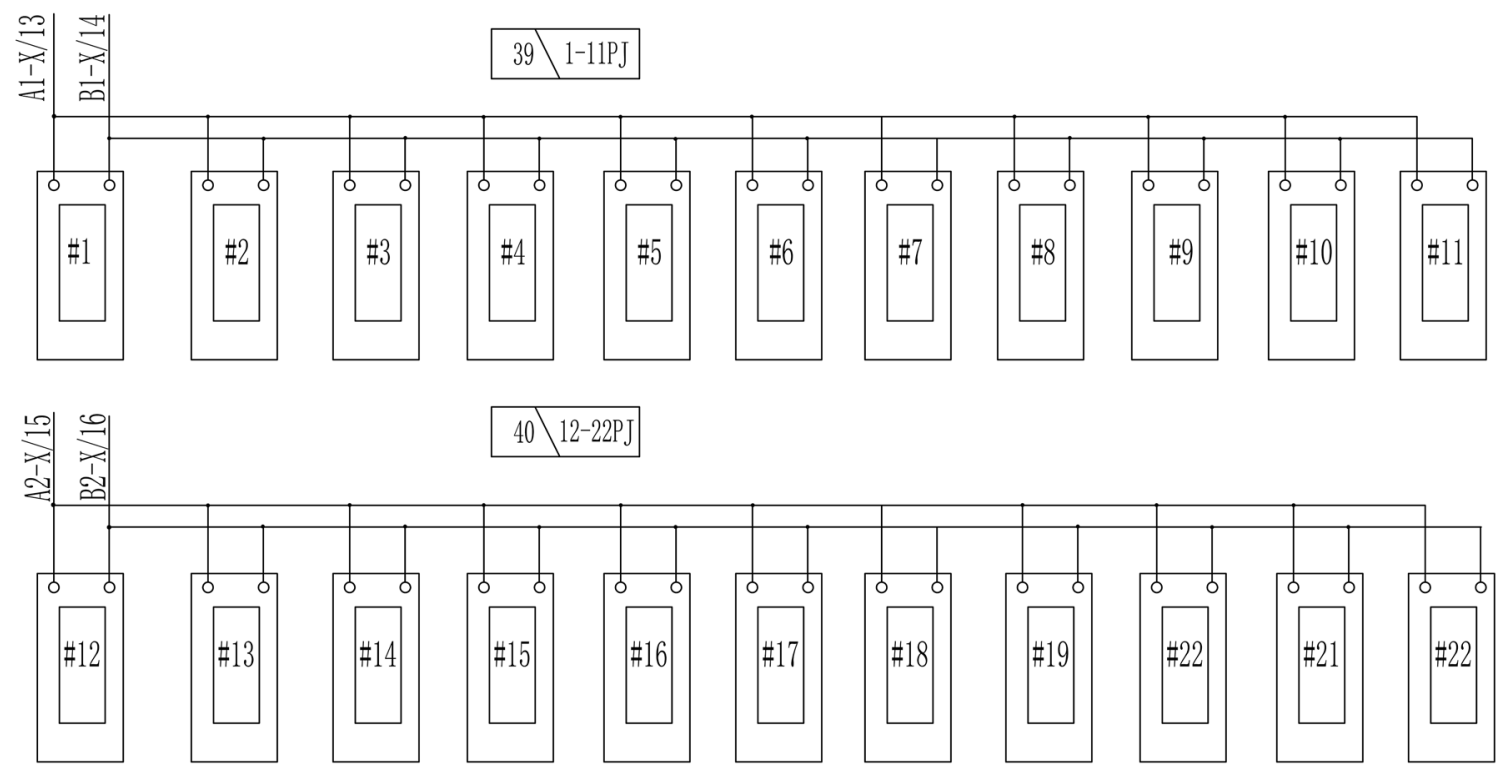

Fig. 12 Electric meter wiring diagram of main distribution cabinet 1 of the Jinchuan Road station

transportation automation systems, the energy saving of Kunming Line 4 is $5 \%$ higher than that of the existing line.
In the future, we will promote the installation of meters in energy-consuming equipment and facilities such as other 


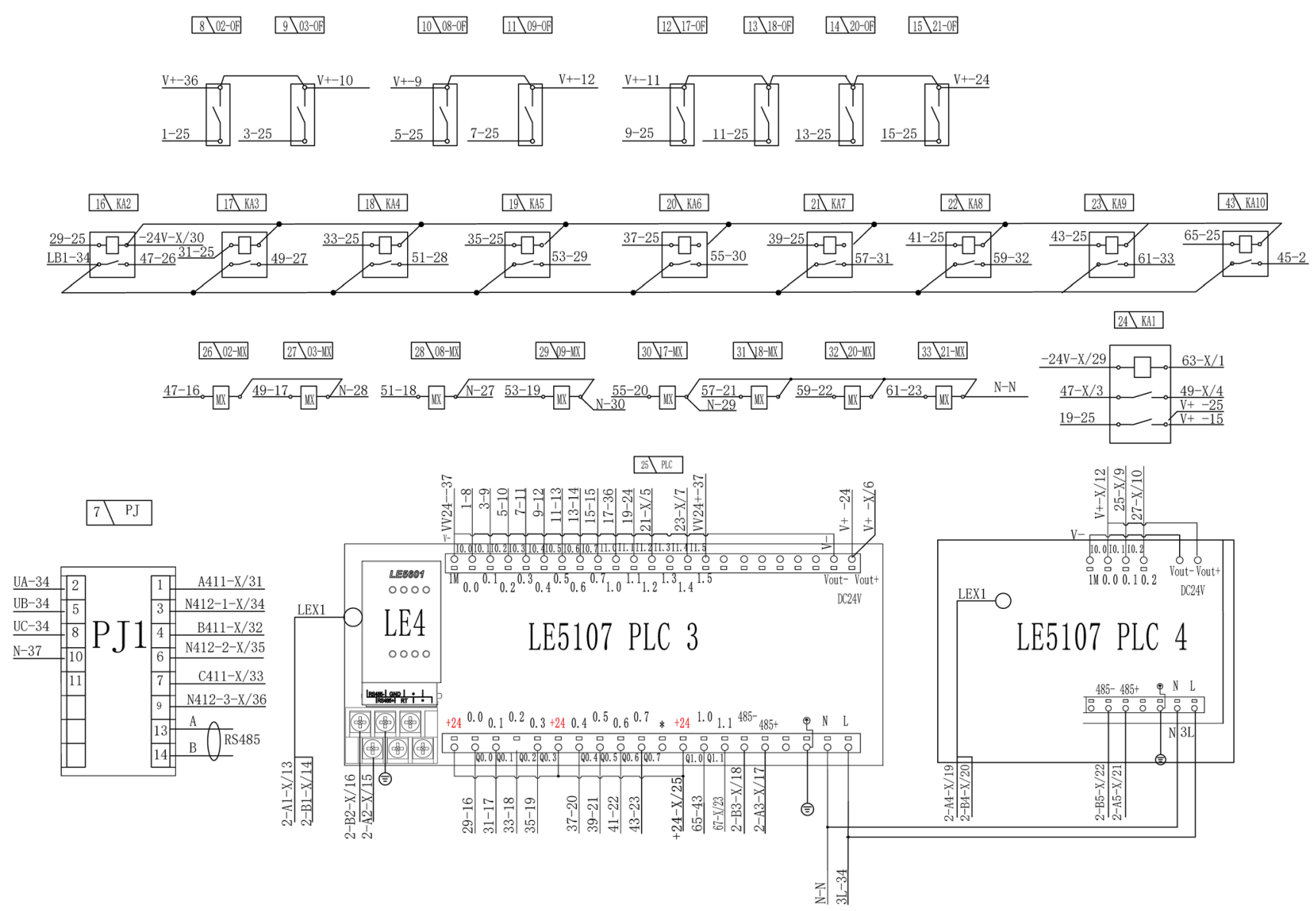

Fig. 13 Wiring diagram of general cabinet 2 of Jinchuan Road station

Fig. 14 Wiring diagram of electric meter in general distribution cabinet 2 of the Jinchuan Road station

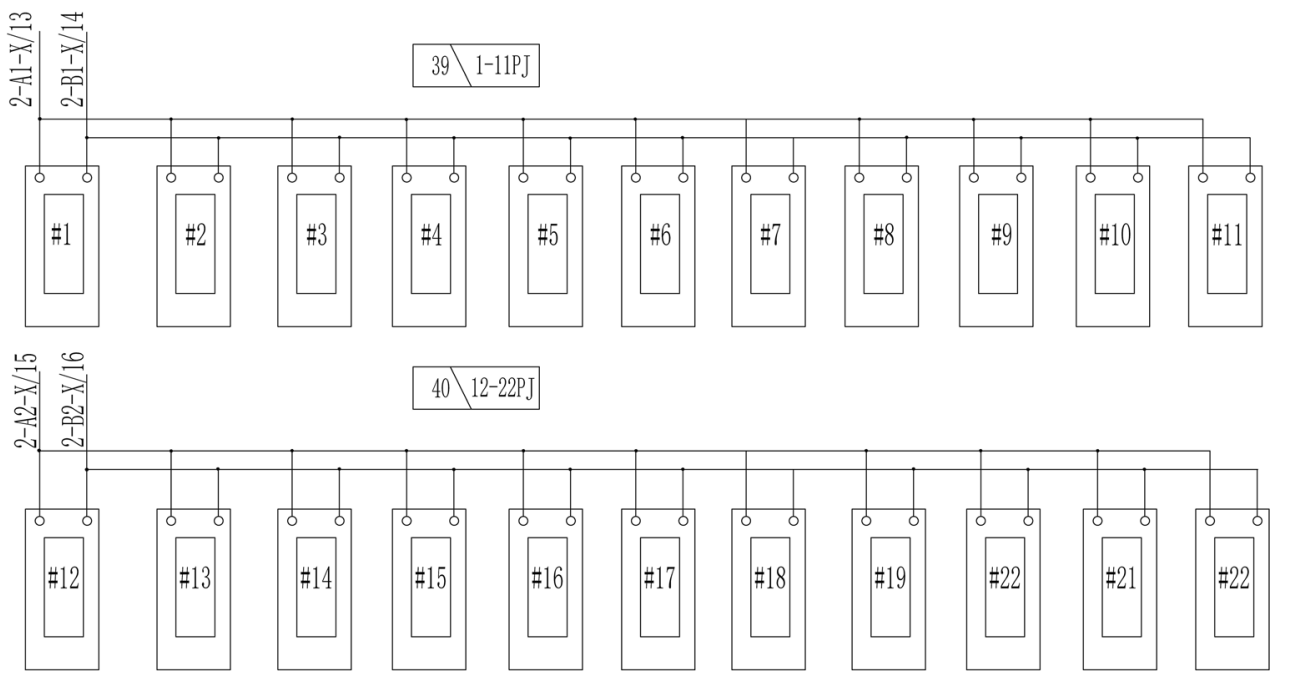

combination with the big data platform to realize energy consumption prediction and provide a scientific and reasonable energy consumption quota for stations and promote the use of the energy consumption quota, in order to facilitate the rational energy consumption of stations and 


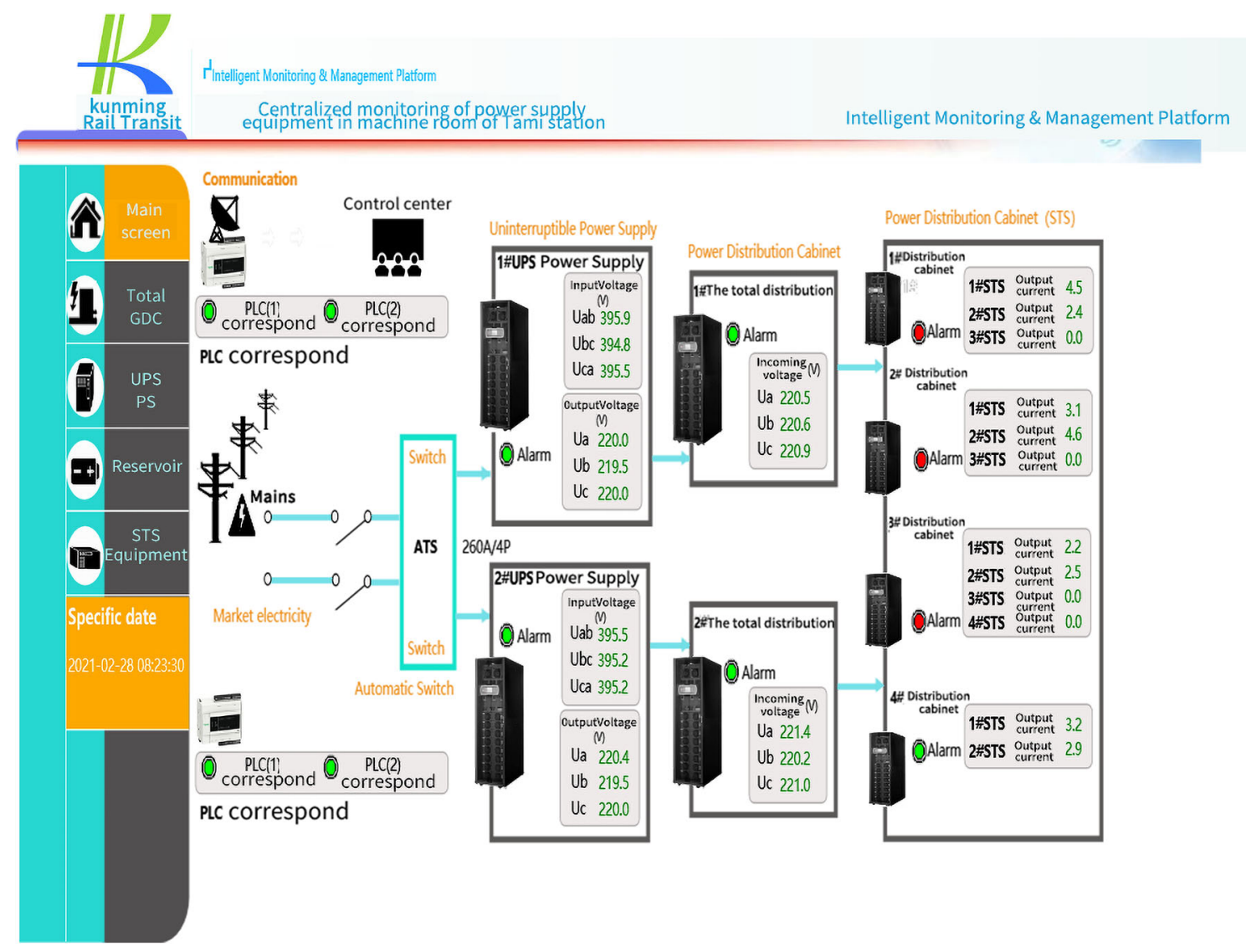

Fig. 15 Centralized monitoring diagram of Tami station

Fig. 16 Measurement data change diagram of Jinchuan Road station
350

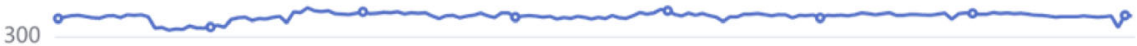

250

200

150

100

50

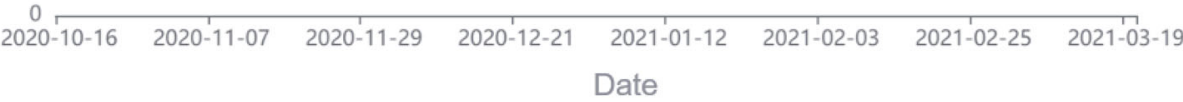


Fig. 17 Diagram of power variation with time at Wujiaying station

Fig. 18 Distribution of average energy consumption of each station
350

$$
300
$$

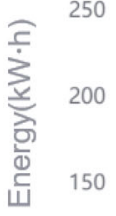

100

50

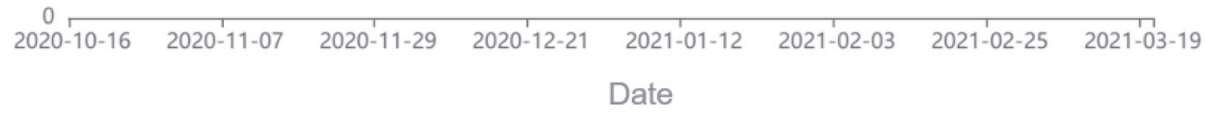

500

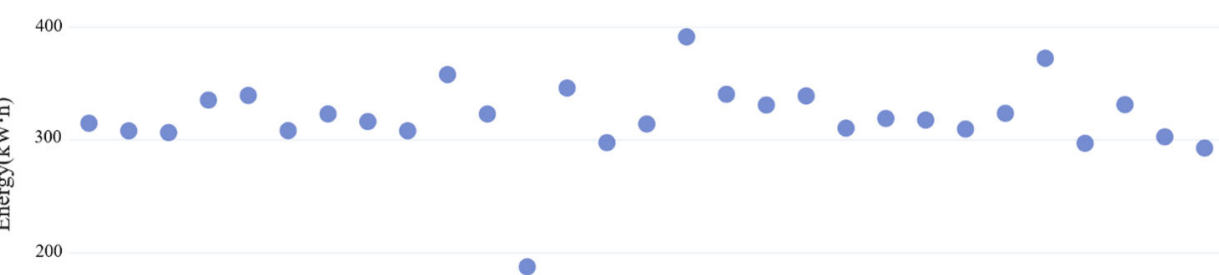

100

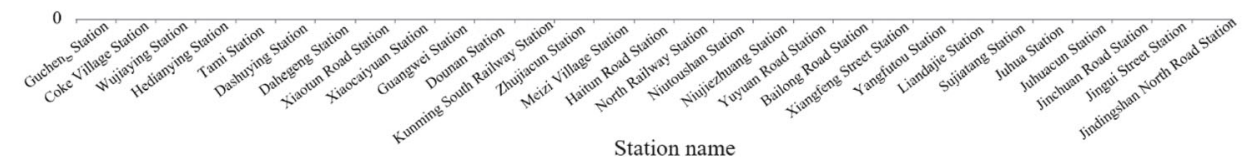


500

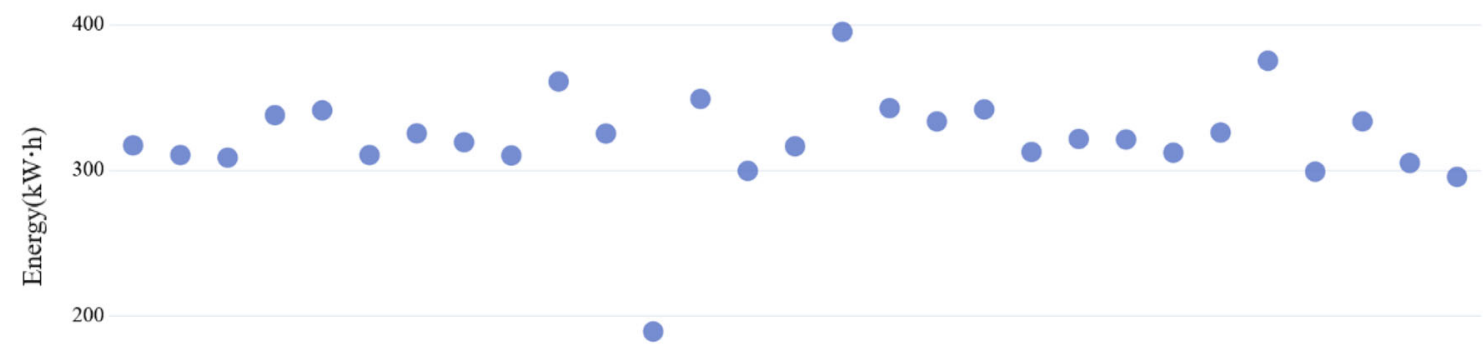

100

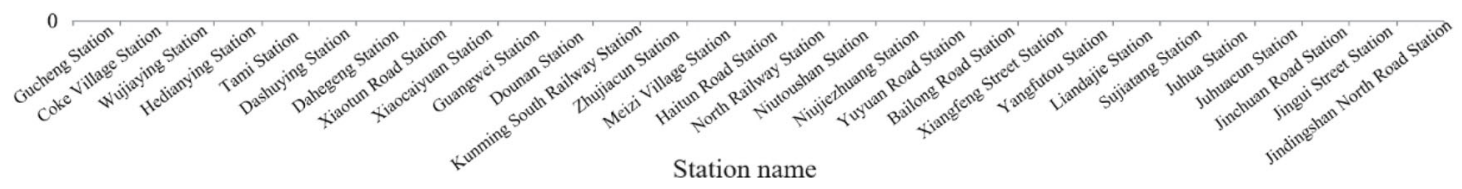

Fig. 19 Median distribution of energy consumption of each station

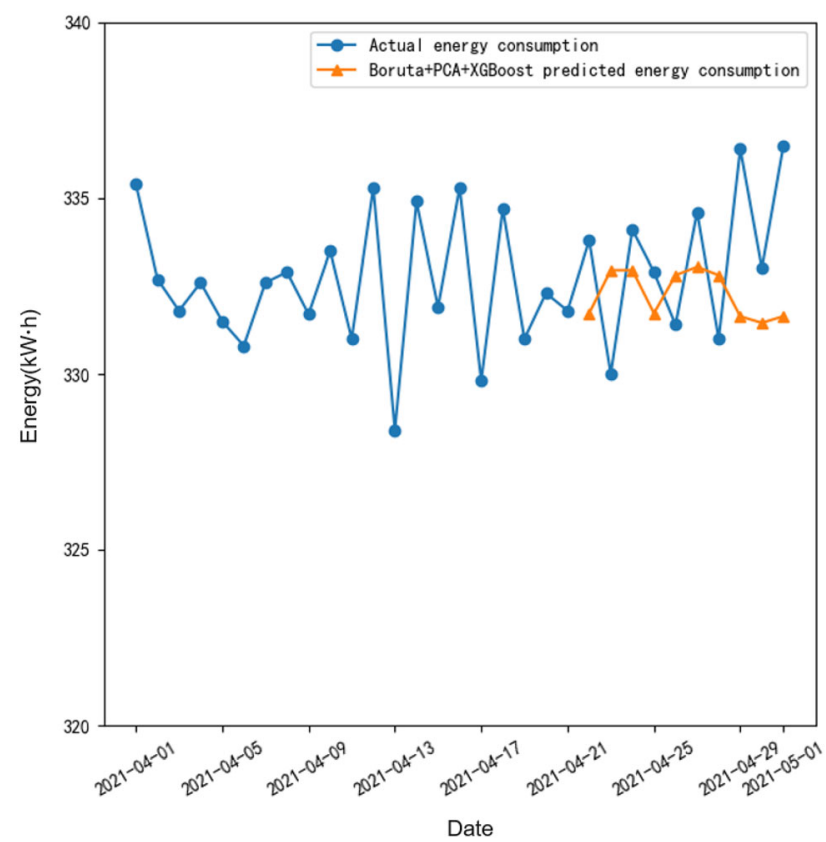

Table 11 Energy consumption prediction results table

\begin{tabular}{lll}
\hline Date & Actual value & Predicted value \\
\hline $2021-04-22$ & 333.8 & 331.62338 \\
$2021-04-23$ & 330 & 332.88132 \\
$2021-04-24$ & 334.1 & 332.88132 \\
$2021-04-25$ & 332.9 & 331.62338 \\
$2021-04-26$ & 331.4 & 332.64853 \\
$2021-04-27$ & 334.6 & 332.788 \\
$2021-04-28$ & 331 & 332.64853 \\
\hline
\end{tabular}

Fig. 20 Energy consumption trend and forecast of Jinchuan Road station 
Fig. 21 24-hour energy consumption distribution diagram of PJ17 meter

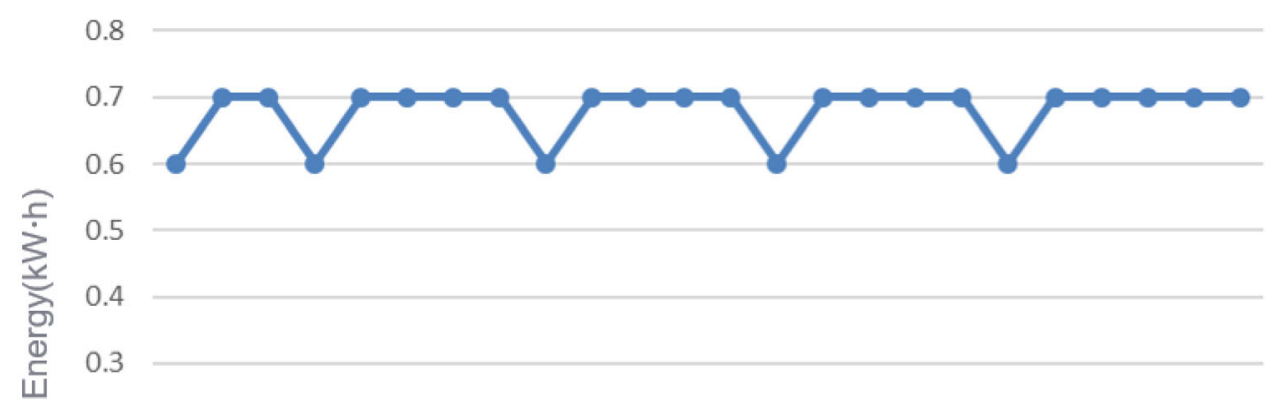

0.2

0.1

0
Fig. 22 Ideal energy consumption distribution of PJ17 meter for $24 \mathrm{~h}$

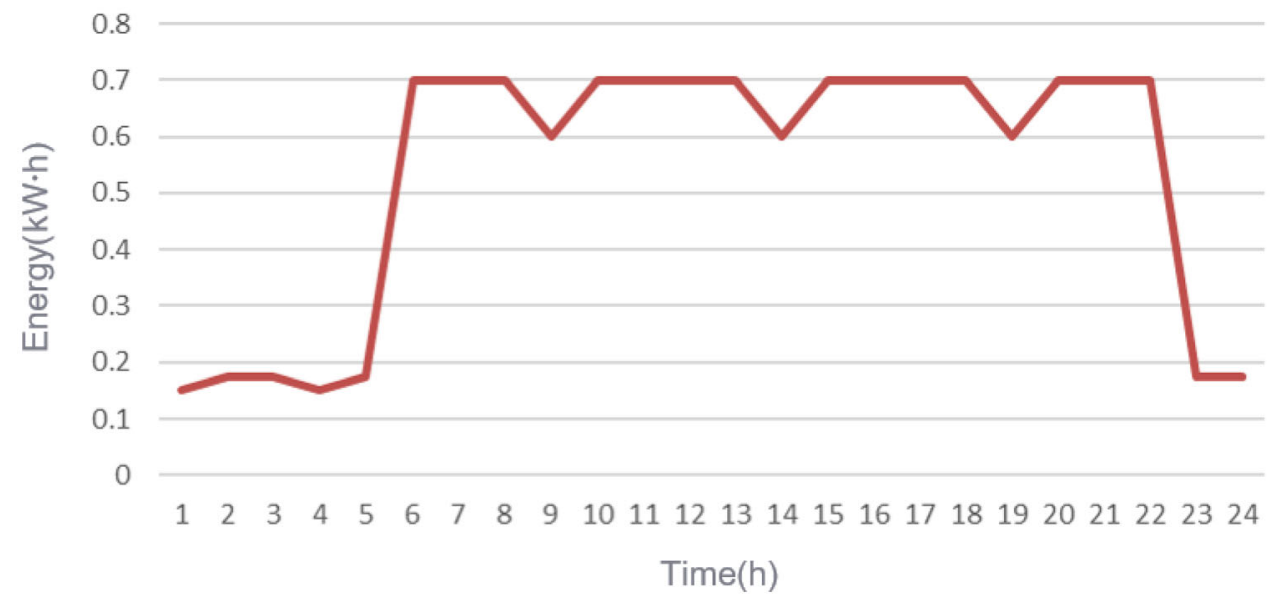

achieve the goal of energy conservation and emission reduction.

Open Access This article is licensed under a Creative Commons Attribution 4.0 International License, which permits use, sharing, adaptation, distribution and reproduction in any medium or format, as long as you give appropriate credit to the original author(s) and the source, provide a link to the Creative Commons licence, and indicate if changes were made. The images or other third party material in this article are included in the article's Creative Commons licence, unless indicated otherwise in a credit line to the material. If material is not included in the article's Creative Commons licence and your intended use is not permitted by statutory regulation or exceeds the permitted use, you will need to obtain permission directly from the copyright holder. To view a copy of this licence, visit http://creativecommons. org/licenses/by/4.0/.

\section{References}

1. Hou XF, Mei JP, Zuo C, Liu GY (2020) Statistical analysis of urban rail transit lines in 2019. Urban Rapid Rail Transit 33(04):1-8
2. Xi JP (2020) Speech at the General Debate of the 75th Session of the United Nations General Assembly. China daily: http://www. chinadaily.com.cn/a/202009/23/WS5f6a640ba31024ad0ba7b1e7. html. Accessed 22 Sept 2021

3. GB 17167-2006, General rules for the allocation and management of energy measuring instruments in energy consuming units. China Standards Press, Beijing.

4. GB 50157-2013, Metro design code. China Building Industry Press, Beijing.

5. Kang HB, Yu JL(2009) Analysis of working principle and development trend of UPS. Power Supply Technol 33(07):637-638

6. Sun B (2010) Principle, operation and maintenance of UPS power supply equipment. Commun Power Technol 27(03):68-70

7. Wang LB, He XN (2003) Classification, key technology analysis and development dynamic prediction of UPS. J Elect Technol 10:21-24

8. Wang ZH, Chen X(2020) Application research of photovoltaic power generation system connected to urban rail transit power supply system. Sol Energy 11:56-61

9. Feng JH(2018) Key technologies and development trend of rail transit permanent magnet motor traction system. Locomotive Electric Drive 06:9-17

10. Sun EX (2020) Design of longitudinal energy-saving slope of urban rail transit line. Urban Rail Transit Res 23(11):126-129 
11. Liu HJ (2019) Research on integrated energy-saving optimization method of urban rail train dispatching control combined with energy storage. Dissertation, Beijing Jiaotong University.

12. Xu AG (2009) Research on regenerative braking energy utilization technology of urban rail transit. Dissertation, Nanjing University of Aeronautics and Astronautics.

13. Yang SP (2019) Passenger oriented multi-objective energy-saving train diagram optimization of urban rail transit. Dissertation, Beijing Jiaotong University.

14. Li C, Wang RZ (2019) Research on energy saving optimization of metro timetable with regenerative braking. Control Theory Appl 36(07):1024-1035

15. Dong SY (2008) Influence law and effective utilization of metro piston wind on metro environment in northern cities. Dissertation, Tianjin University.

16. Yan RQ (2006) Study on the applicability of platform screen door system in China's metro. Dissertation, Southwest Jiaotong University.

17. Sun ZT (2005) Application prospect of PSD system in metro. Urban Rapid Rail Transit 02:4-7

18. Song MH (2009) Research on development trend of energy saving technology of urban rail transit. Eng Construct Des 01:15-19

19. Yang L (2017) Research on energy consumption characteristics and energy saving strategies of metro stations. Dissertation, Tsinghua University.

20. Lu HY, Yin H (2019) Research status of energy conservation in metro stations. Progress of New Energy 7(04):333-345

21. Zhu LJ (2019) Discussion on the application of energy saving and consumption reduction technology in metro power supply system. Electrified Railway 30(03):75-78

22. Li J, Wang L (2020) Discussion and measures analysis on energy conservation management of urban rail transit. Eng Construct Des 15:79-81

23. Cao H (2019) Analysis on measures and promotion of metro energy conservation. Inf Syst Eng 04:80-82

24. Huang MC (2018) Nanjing Metro energy consumption data model. Energy Res Utilization 01:50-53

25. Huang MC, Li GG (2011) Energy supervision system of Nanjing Metro Line 1. Urban Rapid Rail Transit 24(03):95-98

26. Shen WJ (2015) Design and application of metro station energy management system. Electr Technol 10:63-67

27. Zhao GL, Wang YL, Tan YL, Wang Z (2019) Analysis on the construction of Harbin Metro energy management system. Transp Enterprise Manag 34(01):82-84
28. Zhong Q (2014) Energy conservation and consumption reduction -Chengdu Metro energy management system pilot project. Enterprise Technol Develop 33(11):60-62

29. Zhang $\mathrm{T}$ (2012) Current situation and development of Metro energy management system. Instrument Standard Measure $03: 46-48$

30. Long T (2009) Design of metro energy management system. Urban Rapid Rail Transit 22(04):15-17

31. Xie HS, Man CH (2013) Analysis and research on main energy consumption influencing factors and energy saving measures of metro. Modern Urban Rail Transit 04:65-67+71

32. Wang HW (2019) Research on energy consumption prediction and quota standard of urban rail transit stations. Dissertation, Beijing Jiaotong University.

33. Liu S, Wang HW (2020) Study on energy consumption quota standard of urban rail transit station based on case. Transp Syst Eng Inf 20(04):231-235

34. Zhao J (2020) Abnormal value analysis method of traction energy consumption of Urban Rail Trains Based on machine learning. Dissertation, Beijing Jiaotong University.

35. Luo QY, Long J, Chen HX, Liu JY, Li ZF (2020) Time series prediction method of metro station energy consumption based on data mining algorithm. Urban Rail Transit Res 23(06):23-27

36. Dai KC, Wang GP, Zhao C (2015) Building energy consumption prediction modeling based on PCA and RBF. Journal of Fuzhou University (Natural Science Edition) 43(4):512-516

37. Leung PCM, Lee EWM (2013) Estimation of electrical power consumption in metro station design by intelligent approach. Appl Energy 101:634-643

38. Kursa MB, Rudnicki WR (2010) Feature Selection with Boruta Package. J Stat Softw 36(11):1-13

39. Wang ZW, Chen SY, Liu XZ, et al (2017) Energy consumption cost estimation model for rail car operation based on Improved PCA and PSO-LSSVM. Railway Transp Econ 02:8-15

40. Chen T, Guestrin C (2016) Xgboost: A scalable tree boosting system. In: Proceedings of the 22nd ACM SIGKDD International Conference on Knowledge Discovery and Data Mining: 785-794, San Francisco, 2016

41. Xuan XD (2013) Application of energy measurement data in formulating energy consumption quota standards. China Metrology 12:68-70

42. Zhang HY (2020) Talking about energy measurement from enterprise energy conservation and consumption reduction. Appl Energy Technol 10:47-49 